\title{
Stakeholder influences and risks in sustainable supply chain management: a comparison of qualitative and quantitative studies
}

\author{
Tobias Rebs ${ }^{1} \cdot$ Marcus Brandenburg ${ }^{1,2}$. \\ Stefan Seuring ${ }^{1} \cdot$ Margarita Stohler $^{1}$
}

Received: 3 December 2016/Accepted: 2 November 2017/Published online: 15 November 2017

(C) The Author(s) 2017. This article is an open access publication

\begin{abstract}
Stakeholder influences on sustainable supply chain management (SSCM) are of increasing interest for researchers to take into account economic, environmental, and social risks. While extant literature on stakeholder influences or risks in SSCM concentrates on selected issues, a comprehensive review of both stakeholder and risk constructs is missing. Hence, this paper examines stakeholder influences and risks in SSCM, as addressed by conceptual frameworks, empirical studies, and formal models to shed light on the trends and gaps in qualitative and quantitative SSCM research. Based on a content analysis of systematically selected journal publications, the commonalities and differences between the research designs are identified. The findings suggest that the integration of economic risks prevails over the consideration of environmental and social risks. Qualitative studies frequently focus on customers or multiple stakeholders that trigger SSCM and relate to supply, demand, and particularly reputational risks. In contrast, quantitative models rather concentrate on formalizing governmental triggers and operational risks. Thus, mutual stimuli between conceptual, empirical, and model-based SSCM research and their implications for future research directions are derived.
\end{abstract}

Electronic supplementary material The online version of this article (https://doi.org/10.1007/s40685017-0056-9) contains supplementary material, which is available to authorized users.

Tobias Rebs

tobias.rebs@uni-kassel.de

Marcus Brandenburg

marcus.brandenburg@hs-flensburg.de

1 Chair of Supply Chain Management, University of Kassel, Kleine Rosenstr. 1-3, 34117 Kassel, Germany

2 School of Business, Flensburg University of Applied Sciences, Kanzleistr. 91-93, 24943 Flensburg, Germany 
Keywords Sustainable supply chain management - Stakeholder influences · Risk management · Literature review · Conceptual frameworks · Empirical studies · Formal models

\section{Introduction}

Sustainable supply chain management (SSCM) has become an established field of research. Currently, SSCM plays a crucial role in mature markets as well as in emerging economies (Esfahbodi et al. 2016). However, major trends and shortfalls in SSCM research include the need to comprehensively address stakeholder influences and to elaborate upon appropriate approaches to SSCM performance measurement (Pagell and Shevchenko 2014; Reefke and Sundaram 2017). Various conceptual frameworks provide definitions (Ahi and Searcy 2013) and systematize key constructs for SSCM research (Seuring and Müller 2008a, b), while empirical studies on the state of SSCM development (Carter and Easton 2011) and formal models for SSCM (Seuring 2013; Brandenburg et al. 2014) illustrate how to integrate environmental and social sustainability factors into supply chain management (SCM). Besides intra-organizational activities and reverse operations, the inter-organizational perspective on the forward supply chain (SC) is highly relevant. Moreover, pressures and incentives from governments, customers, and other stakeholders that trigger the implementation of SSCM (Seuring and Müller 2008b) as well as sustainable risk management are of particular interest in scientific literature (Hofmann et al. 2014). Relationship management with stakeholders and sustainable risk management in SCs are identified as major themes and research opportunities in SSCM (Reefke and Sundaram 2017).

Recent literature shows that quantitative models formalize stakeholder pressures and incentives for green or sustainable SCM and assess sustainability risks (Brandenburg and Rebs 2015). However, conceptual and empirical research that focuses on SSCM triggers and risks has not been compared to the developments and directions of formal models. These research streams might even appear somewhat disconnected. Hence, this paper seeks to compare how stakeholder triggers and risks are addressed by conceptual frameworks, empirical studies, and formal models. Based on commonalities and differences of focused constructs, mutual stimuli and guidelines for future research are addressed.

Thus, we pose the following research questions to explore the current state of research and future research directions:

1. How are stakeholder influences on SSCM addressed in related research?

2. How are sustainability-related risks conceptualized and evaluated in SSCM research?

3. Which guidelines and future prospects are derived from commonalities and differences of conceptual frameworks, empirical studies, and formal models?

The remainder of this paper is organized as follows: In Sect. 2, related reviews are summarized, and the research questions of this literature review are justified. In Sect. 3, the research methodology is described, and the methodological rigor is 
discussed. Section 4 contains the results of the content analysis. Subsequently, Sect. 5 summarizes the main findings and presents a conceptual framework of stakeholder influences and SSCM risks. Section 6 outlines the contributions and limitations of this study and suggests guidelines for future research based on the key findings. Section 7 concludes this paper. Additionally, the references of all journal articles analyzed for this literature review are provided as electronic supplementary material.

\section{Background and terminology}

In this section, an overview of extant reviews of related literature is presented. In addition, constructs and terminology of stakeholder influences and SSCM risks are introduced. Based on this, the motivation and contribution of the presented study is justified.

\subsection{Extant reviews of related literature}

Research on stakeholder triggers for SSCM and sustainability-oriented risk management in SCs takes various foci and methods to investigate these topics conceptually, empirically, and by applying formal models. An overview of related literature reviews is given to point out recent research advances and to position this paper in the context of existing studies. Table 1 summarizes relevant literature reviews on triggers and risks for (sustainable) SCM. A remarkable share of articles was published within the last 2 years, and nearly all reviews consider SC risks. Two reviews (Seuring and Müller 2008b; Brandenburg and Rebs 2015) consider both the

Table 1 Literature reviews on sustainability-oriented stakeholder triggers and risks in SCM

\begin{tabular}{llllll}
\hline Author(s) and year & Sample size & $\begin{array}{l}\text { Research } \\
\text { designs }\end{array}$ & TBL focus & $\begin{array}{c}\text { Triggers } \\
\text { Risk } \\
\text { management }\end{array}$ \\
\hline Seuring and Müller (2008b) & 191 & General & Holistic & X & X \\
Colicchia and Strozzi (2012) & 55 & General & None & - & X \\
Miemczyk et al. (2012) & 73 & General & Holistic & - & X \\
Brandenburg and Rebs & 185 & Models & Holistic & X & X \\
$\quad$ (2015) & 489 & Models & Holistic & - & X \\
Fahimnia et al. (2015) & Not disclosed & Models & Not explicit & - & X \\
Heckmann et al. (2015) & 224 & General & None & - & X \\
Ho et al. (2015) & 49 & Empirical & Holistic & X & - \\
Meixell and Luoma (2015) & 16 & Conceptual & Not explicit & - & X \\
Rangel et al. (2015) & 64 & General & Not explicit & - & X \\
Choi et al. (2016) & & &
\end{tabular}


triggers and risks for SSCM, while one study (Meixell and Luoma 2015) focuses on stakeholder influences only.

Most of the reviews focus on risk management only. Colicchia and Strozzi (2012) combine a systematic literature review and citation network analysis to unveil evolutionary patterns of research on SC risks. They point out that dealing with SC risks involves a number of trade-offs and that collaboration across the SC or network is a measure to estimate and mitigate risks. Focusing on purchasing, Miemczyk et al. (2012) systematically review extant studies on the dyad, chain, and network levels and find that environmental sustainability in dyadic contexts prevails, thus pointing to the shortfalls of addressing social aspects and sustainability risks beyond the dyad level. Fahimnia et al. (2015) employ citation network analysis to identify research clusters of SC risks in quantitative modeling research and emphasize the increasing relevance of sustainability risk analysis. Steps toward a systematization of SC risks are taken by Heckmann et al. (2015), who compare risk definitions of conceptual and empirical studies with regard to quantitative measurement in formal models. Ho et al. (2015) review extant literature on SC risk management and find several research gaps, for instance the lack of considering infrastructural risks and the limited ability to study several risk factors simultaneously. Rangel et al. (2015) propose a comprehensive SC risk classification based on existing conceptual frameworks to further the consensus between different risk classifications. Choi et al. (2016) put a wider focus on enterprise risk management, including operational SC risks.

Beyond SSCM risks, Seuring and Müller (2008b) show that pressures and incentives for SSCM are central constructs to study. Brandenburg and Rebs (2015) analyze formal SSCM models with regard to their ability to integrate stakeholder triggers and SSCM risks and formulate directions for future SSCM modeling research. Meixell and Luoma (2015) systematically review empirical studies on stakeholder pressures and find that stakeholder pressure leads to increased sustainability orientation.

In sum, existing literature reviews mostly focus on either risks or triggers for SSCM. Moreover, many studies are limited with regard to the focused research designs. Meixell and Luoma (2015), for instance, use a comparably small sample consisting of both intra- and inter-organizational studies and include only empirical papers dealing with stakeholder pressures. In contrast, the paper at hand additionally covers studies that assess risks for SSCM. Hence, to our best knowledge this paper is the first to compare different research designs, i.e., conceptual and empirical studies as well as formal models, with regard to SSCM triggers and risks. The approach of comparing empirical and quantitative modeling papers sheds light on mutual stimuli and future research directions.

The remainder of this section summarizes the state of research with regard to stakeholder triggers and SSCM risks and determines the scope of definitions employed in this study. Subsequently, the motivation and contribution of our study is outlined, and the research questions are elaborated. 


\subsection{Stakeholder influences on SSCM}

Stakeholders are individuals or groups that can influence the achievement of a corporation's goals or that are affected by the company's performance (Freeman Freeman 1984, 2010). In the context of SCM, stakeholders may be part of the considered SC (e.g., in the form of suppliers or customers) or, while being SCexternal actors, recognize the impact of the SC actors' performance. According to this distinction, stakeholders comprise primary stakeholders, such as customers and suppliers or employees and top managers, and secondary stakeholders, such as government and non-governmental organizations (NGOs), trade associations and competitors, or media and community (Meixell and Luoma 2015).

Besides economic objectives, stakeholder groups exert pressures on focal companies to enhance the sustainability performance of their SCs. Governmental pressures and incentives typically originate from local, national, and international regulations set by national governments or transnational regulatory bodies. The competitive advantage and reputation of a firm are influenced by external stakeholder groups that force companies to transparently monitor and control the sustainable SC performance (Seuring and Müller 2008b). In a more aggregate approach, which is applied in the paper at hand, these stakeholder groups are categorized as government, customers, and other stakeholders (Seuring and Müller 2008b).

Influential triggers that amplify the SSCM implementation comprise pressures, seen as pushing factors forcing SC members to act sustainably, and incentives, regarded as pulling factors that foster the development of SSCM (Brandenburg and Rebs 2015). These insights are the basis for the terminology used in the study at hand. In this study, we assess stakeholder influences as an obligation to manage the SC sustainably or as a penalty for unsustainable behavior, which reflect pressures, as well as the motivation or stimulus for sustainability in the SC, which can be understood as incentives.

\subsection{SSCM risks}

SCM research distinguishes between "ordinary supply chain risks" that are connected to the material and financial flow and "sustainability-related supply chain risks" that are triggered by stakeholder reactions (Hofmann et al. 2014: 167).

Traditional SC risks can be grouped into supply, demand, product, and information risks (Tang 2006). In this context, agency theory applies to SCMrelated risks with regard to information asymmetries between the buying and the supplying company, i.e., supply and demand risks (Eisenhardt 1989). Thus, the relationship between SC actors as well as to their stakeholders is central to managing risks and rewards in SCM (Fayezi et al. 2012). Rao and Goldsby (2009) categorize SC risks into environment, industry, and organizational risks as well as problem-specific and decision-maker risks. Similarly, Ghadge et al. (2012) show that SC risks are based on uncertainties of external parameters. Pfohl et al. (2010) emphasize the negative influences of short-term disturbances and long-term disruptions on performance factors, such as customer value, cost, time, and quality. 
Such disturbances and disruptions can be prevented by SC security and resilience strategies, especially under consideration of the threat of risk migration (Tukamuhabwa et al. 2015). Khan and Burnes (2007) encourage future SC risk management research and call for wider attention to the nature of risks and more empirical research into the ways in which risks are managed in SCs.

Sustainable operations place a particular emphasis on managing economic, environmental, and social sustainability risks (Jaehn 2016). The sustainable management of SC risks is emphasized as an important strategic element. Carter and Rogers (2008) see risk management as a supporting facet of SSCM that includes the requirements of contingency planning, supply disruptions, and outbound SCs. Seuring and Müller (2008b: 1703) formulate "supplier management for risks and performance" and "supply chain management for sustainable products" as basic strategies for SSCM. The authors explain that risk management for SSCM shall improve SC performance not only by reasonable trade-offs but also by a greater number of win-win (-win) situations between the sustainability dimensions of the triple bottom line (TBL). Placing a narrower focus on sustainable purchasing management at the firm and inter-organizational SC levels, Miemczyk et al. (2012) identify operationalized environmental and social measures. Thus, supplier evaluation and selection based on environmental and social standards is confirmed as a crucial element of SSCM. For instance, social issues can be managed by communication, compliance, and supplier development strategies to address the associated risks (Yawar and Seuring 2017). In the study at hand, sustainability risks are categorized as economic, environmental, and social, as suggested by Seuring and Müller (2008b). Following Tang (2006), supply, demand, product, and information are used as traditional SC risk categories.

\subsection{Motivation and contribution}

Related literature reviews elaborate on either stakeholder triggers or SSCM risks by trying to categorize related aspects; thus, a recent review that covers both areas and different research designs simultaneously is not available. Only Seuring and Müller (2008b) take different types of conceptual, empirical, and quantitative modeling literature into account that holistically consider sustainability-related aspects of SCM. Other reviews exclusively concentrate on formal models (Brandenburg and Rebs 2015; Fahimnia et al. 2015; Heckmann et al. 2015), empirical studies (Meixell and Luoma 2015), or conceptual frameworks (Rangel et al. 2015). The focus on SC risks (e.g., Miemczyk et al. 2012) is clearly dominant with nine out of 10 related reviews, whereas some of these reviews do not even explicitly consider the TBL of sustainability (Colicchia and Strozzi 2012; Ho et al. 2015; Choi et al. 2016). In contrast, stakeholder triggers for SSCM are comparably seldom investigated.

A topical overlap between stakeholder pressures and risks for SSCM can be observed. Interrelationships exist, for instance, with regard to reputation loss as a pressure for SSCM implementation (Seuring and Müller 2008b) and reputational risks (Roehrich et al. 2014) or when customer pressures translate into demand risks (Tang 2006; Pfohl et al. 2010). A recent definition by Heckmann et al. (2015: 130) captures SC risks as “( $\cdots)$ the potential loss for a supply chain in terms of its target 
values of efficiency and effectiveness evoked by uncertain developments of supply chain characteristics whose changes were caused by the occurrence of triggeringevents." Since triggering events can be caused by various stakeholder influences, a crucial relationship between SSCM risks and stakeholder influences can be assumed. Hence, a literature review that integrates both dimensions, i.e., stakeholder triggers and risks for SSCM, is deemed necessary to capture the definitions and measurements of these linked dimensions. Moreover, it is essential to compare quantitative with qualitative studies with regard to the consideration of stakeholder influences and SSCM risks. Such a study helps in evaluating the extent of operationalization in formal models, but to the best of our knowledge it is not available in the scientific literature to date. In sum, recent reviews show shortfalls mainly with regard to the lack of sustainability focus, the types of reviewed research designs, and the isolated investigation of either risks or stakeholder influences in SSCM.

\section{Methodology}

A systematic literature review based on a content analysis (Mayring 2010) is adequate to elaborate on the three research questions formulated in the introduction section (Krippendorff 1980; Fink 2009; Seuring and Gold 2012). In accordance with Seuring and Gold (2012), the methodology follows a four-step approach-material collection, descriptive analysis, category selection, and material evaluation-as described subsequently.

According to Tranfield et al. (2003), a final outcome of a systematic literature review should include the dissemination of findings to synthesize knowledge and give guidelines for future research and managerial practice. Hence, directions for future research are outlined based on the insights gained from the study at hand, and, furthermore, a conceptual framework of stakeholder influences and risks in SSCM is developed. This will help to deepen the understanding of the role of stakeholder influences and to design formal modeling approaches that reflect SSCM risks.

\subsection{Material collection}

The sample papers have been carefully selected to take into account relevant publications to derive rigorous insight. Papers have been searched using Web of Science by structured keyword searches in the abstract, title, and keywords. Keywords comprise strings including "sustain*", "supply chain", "sourcing", "logistics", "manufacturing", "risk", "stakeholder", "pressure", "incentive", "model", and their combinations. Additionally, a journal-specific search in logistics- and transportation-related publications helped to complement the sample via further relevant papers.

Paper validation, i.e., deciding about the inclusion of a paper in the sample, was based on predefined criteria. Ambiguity or doubts were resolved through discussion within the research team. Each paper of the compiled sample matches the following criteria: 
- The paper is written in English and published between 1994 and 2014 in a peerreviewed international scientific journal.

- The paper deals with forward SCM on the inter-organizational level.

- The paper elaborates on the environmental or the social dimension of sustainability.

- The paper includes stakeholder influences or SC risk management.

Papers that deal with intra-organizational functions and processes of SCM or studies that elaborate on an aggregate, macroscopic level of analysis are deliberately excluded from the sample. As a further demarcation, studies on reverse and closedloop SCs are not taken into account because of the particularities of backward SC processes that have been reviewed extensively (see, e.g., Govindan et al. 2015; Govindan and Soleimani 2017).

\subsection{Descriptive analysis}

The descriptive analysis of the distribution of articles over research methodologies, time, and journals serves to examine developments in this research area.

\subsection{Category selection}

The sample papers are analyzed against the three structural dimensions "Supply Chain Management", "Sustainability" and "Sustainable Supply Chain Management" and related coding categories deduced from conceptual frameworks and literature reviews in the field of SSCM (see Table 2). The analytical categories comprise (1) the primary actor of analysis and (2) the level of analysis, as suggested by Halldórsson and Arlbjørn (2005), (3) the function of analysis based on Brandenburg et al. (2014) and supplementary inductive coding, (4) the industry focus categorized by an inductively developed coding scheme, (5) the TBL of sustainability (Elkington 1998; Dyllick and Hockerts 2002), (6) the stakeholder triggers for SSCM including "government", "customer", and "other stakeholders" (Seuring and Müller 2008b) that comprise primary and secondary stakeholders (Clarkson 1995; Meixell and Luoma 2015), and (7) risk management categories, as conceptualized by Tang (2006) and brought into context of sustainability by Seuring and Müller (2008b).

The following remarks explain the analytic categories in greater detail. For the SCM-related structural dimension, the primary actor of analysis is coded as the SC actor emphasized in the respective sample paper, i.e., a manufacturer, carrier, or retailer. In some cases, multiple actors may be considered equally. The level of analysis considers the inter-organizational networks of at least two firms linked in a dyad, a linear chain, or a non-linear network with converging and diverging precedence relationships. The function of analysis determines the functional context in which the respective sample paper is settled. It may be a rather strategic function, e.g., SCM or standards/certifications, as opposed to rather tactical or operational functions, e.g., production or logistics. The industry of analysis may be specified in the sample papers, or it may remain nonspecific or generic. 
Table 2 Structural dimensions and analytic categories for the content analysis

\begin{tabular}{|c|c|}
\hline $\begin{array}{l}\text { Structural } \\
\text { dimension }\end{array}$ & Analytic categories \\
\hline \multicolumn{2}{|c|}{ Supply chain management } \\
\hline $\begin{array}{l}\text { Primary actor } \\
\text { of analysis }{ }^{\mathrm{a}}\end{array}$ & Manufacturer, carrier, retailer, multiple \\
\hline $\begin{array}{l}\text { Level of } \\
\text { analysis }^{\text {a }}\end{array}$ & Dyad, chain, network, other \\
\hline $\begin{array}{l}\text { Function of } \\
\text { analysis }^{\text {a }}\end{array}$ & $\begin{array}{l}\text { Environmental/corporate social responsibility (CSR) } \\
\text { management, logistics, materials management, } \\
\text { network design, pricing, product development, } \\
\text { production, SCM, sourcing, standards/ } \\
\text { certifications, technology/IT }\end{array}$ \\
\hline $\begin{array}{l}\text { Industry } \\
\text { focus }^{\mathrm{a}}\end{array}$ & $\begin{array}{l}\text { Agriculture, apparel/textile, automotive, biofuel, } \\
\text { chemicals/pharmaceuticals, electronics, energy, } \\
\text { engineering, food/beverages, furniture, metal/ } \\
\text { mining, public procurement, retail, tourism, } \\
\text { transportation, multiple, undisclosed/generic }\end{array}$ \\
\hline \multicolumn{2}{|l|}{ Sustainability } \\
\hline $\begin{array}{l}\text { TBL } \\
\text { dimensions }^{b}\end{array}$ & Economic, environmental, social \\
\hline \multicolumn{2}{|c|}{ Sustainable supply chain management } \\
\hline $\begin{array}{l}\text { Stakeholder } \\
\text { triggers }^{\mathrm{b}}\end{array}$ & $\begin{array}{l}\text { Government, customers, other stakeholders } \\
\text { Other stakeholders include: further primary } \\
\text { stakeholders (suppliers, employees, shareholders, } \\
\text { top management), further secondary stakeholders } \\
\text { (NGOs, competitors, local community, media, trade } \\
\text { unions, investors, wider public), } \\
\text { nonspecific/generic }\end{array}$ \\
\hline $\begin{array}{l}\text { Risk } \\
\text { management }^{\mathrm{b}}\end{array}$ & $\begin{array}{l}\text { Supply, demand, product, information risks } \\
\text { Economic, environmental, social risks }\end{array}$ \\
\hline
\end{tabular}

References

Halldórsson and Arlbjørn (2005)

Halldórsson and Arlbjørn (2005)

Brandenburg et al. (2014) and inductive coding scheme

Inductive coding scheme

\author{
Elkington (1998), Dyllick \\ and Hockerts (2002)
}

Seuring and Müller (2008b)

Clarkson (1995), Meixell and Luoma (2015)

Tang (2006)

Seuring and Müller (2008b)

\footnotetext{
a Single classification only

${ }^{\mathrm{b}}$ Multiple classification possible
}

For the TBL dimensions of sustainability, combinations of economic, environmental, and social aspects are included in the analysis and, thus, multiple coding of these three aspects is allowed as well as for the SSCM-related dimensions that cover the stakeholder and risk perspectives. Stakeholder triggers arise from government, customers, and other stakeholders. To further distinguish between other stakeholders, different primary and secondary stakeholder groups are categorized. Risk management categories comprise conventional SCM risk categories, i.e., supply, demand, product, and information risks, as well as the categorization toward the TBL of sustainability, i.e., economic, environmental, and social risks.

\subsection{Material evaluation}

Bibliometric analysis is conducted using the citation software HistCite ${ }^{\mathrm{TM}}$ (version 12.03.17), complemented by Excel spreadsheet analysis, to unveil linkages within 
and between research streams. To this end, three citation scores are considered. The local citation score (LCS) reflects the number of citations to a sample paper from within the collected sample, while the local cited references score (LCR) shows the number of citations in a sample article's reference list to other articles within the sample. The global citation score (GCS) indicates the number of references to a paper in Web of Science.

After coding the sample papers against the categories described above, the occurrence frequencies of categories are numerically analyzed to reveal the dominant trends and underrepresented constructs. A cross-category analysis of the co-occurrence of coding dimensions and categories enables the correlations between SCM, sustainability, and SSCM constructs to be explored. Furthermore, the interpretation of the results of content analysis is complemented by an in-depth analysis of full text elements.

\subsection{Methodological rigor}

To ensure high-quality research and methodological rigor, issues of replicability, reliability, and validity are considered in this study. The logic of material collection, i.e., the search for papers, and the paper validation test criteria, i.e., the decision to select a paper for the sample, are documented to ensure the replicability of the sampling process. Reliability in the course of content analysis is achieved by involving several coders who discussed coding differences in cases of ambiguity (Seuring and Gold 2012). Construct validity is gained by deductively deriving the coding categories for content analysis from related acknowledged theoretical frameworks. Furthermore, the study at hand was presented and discussed at several conferences ${ }^{1}$.

\section{Analysis of SCM, sustainability, and SSCM constructs}

This section contains the results of the analysis. First, the descriptive analysis outlines general characteristics of the collected articles; second, the bibliometric analysis of the paper sample serves to explore of the connectedness of qualitative and quantitative SSCM research with regard to stakeholder influences and SSCM risks; and third, the findings from the content analysis with regard to the selected coding categories are presented.

\footnotetext{
Par39 3rd International EurOMA Sustainable Operations and SC Forum (11-12 April 2016, Lancaster, England, UK), 78. Jahrestagung des Verbands der Hochschullehrer für Betriebswirtschaft (VHB)/78. Annual Conference of the German Academic Association for Business Research (18-20 May 2016, Munich, Germany), Herbsttagung der Wissenschaftlichen Kommission Nachhaltigkeitsmanagement des VHB/Autumn Meeting of the Scientific Commission Sustainability Management of the German Academic Association for Business Research (VHB) (05-07 October 2016, Dresden, Germany).
} 


\subsection{Descriptive analysis}

The descriptive analysis shows the distribution of sample papers per research methodology as well as the distribution with regard to the year of publication and the relevant journals.

\subsubsection{Distribution of papers over research methodologies}

The paper sample consists of 41 empirical studies comprising 27 case studies and 14 surveys and 49 theoretical papers, including 10 conceptual papers and 39 formal models (see Table 3 ). Thus, a relatively even share of empirical and theoretical studies and a balance of qualitative and quantitative analyses is observed.

The distribution of formal models, i.e., theoretical-quantitative papers (see Table 3), with regard to the model type is presented in Table 4 to prepare the analysis of risk management categories in Sect. 4.3.7. Formal models can be categorized as deterministic or stochastic as well as descriptive or normative (Shapiro 2007). They are applied to quantitatively assess the complex interplay of different factors of sustainable supply networks or to support decision-making and SC planning under consideration of sustainability criteria. The high share of deterministic approaches suggests that aspects of vagueness and uncertainty are comparably underrepresented in model-based SSCM research. The prevalence of normative models in comparison to descriptive ones shows that identifying optimized solutions for SSCM problems has become highly relevant.

\subsubsection{Distribution of sample papers over time}

The distribution of publications per year (see Fig. 1) shows little research activity until 2007 followed by a slight increase in publications per year. Quantitative models show earlier growth than empirical studies. The four earliest published formal models in the paper sample present approaches to decision support in specific industry contexts. Two are based on the first conceptualizations of green supplier management in the automotive industry (Noci 1997) and in paper and apparel manufacturing (Handfield et al. 2002). Two others are applied for renewable energy exploitation projects (Georgopoulou et al. 1998) or shared-savings for indirect material in the chemical industry (Corbett and DeCroix 2001). However, the numbers of empirical studies increased in 2013 and 2014.

These observations can be interpreted as follows. Simply classifying empirical studies as used for theory development and formal models as used for theory testing would in general certainly fall short. The early quantitative models are rather indicative of some kind of problem identification. The need to measure and manage the environmental performance of suppliers (Noci 1997; Handfield et al. 2002), the conflicts between suppliers and buyers regarding economic and environmental impacts (Corbett and DeCroix 2001), and the design and implementation of decision support systems for sustaining renewable energies exploitation (Georgopoulou et al. 1998) exemplify the indicative nature of model-based studies. Overall, a stronger interest in and need for empirical research is indicated, as the relationships between 
Table 3 Distribution of papers over research methodologies

\begin{tabular}{llll}
\hline & Empirical & Theoretical & Total \\
\hline Qualitative & 27 & 10 & 37 \\
Quantitative & 14 & 39 & 53 \\
Total & $\mathbf{4 1}$ & $\mathbf{4 9}$ & $\mathbf{9 0}$ \\
\hline
\end{tabular}

Table 4 Distribution of formal modeling papers regarding the model type

\begin{tabular}{llll}
\hline & Deterministic & Stochastic & Total \\
\hline Descriptive & 8 & 8 & 16 \\
Normative & 21 & 2 & 23 \\
Total & $\mathbf{2 9}$ & $\mathbf{1 0}$ & $\mathbf{3 9}$ \\
\hline
\end{tabular}

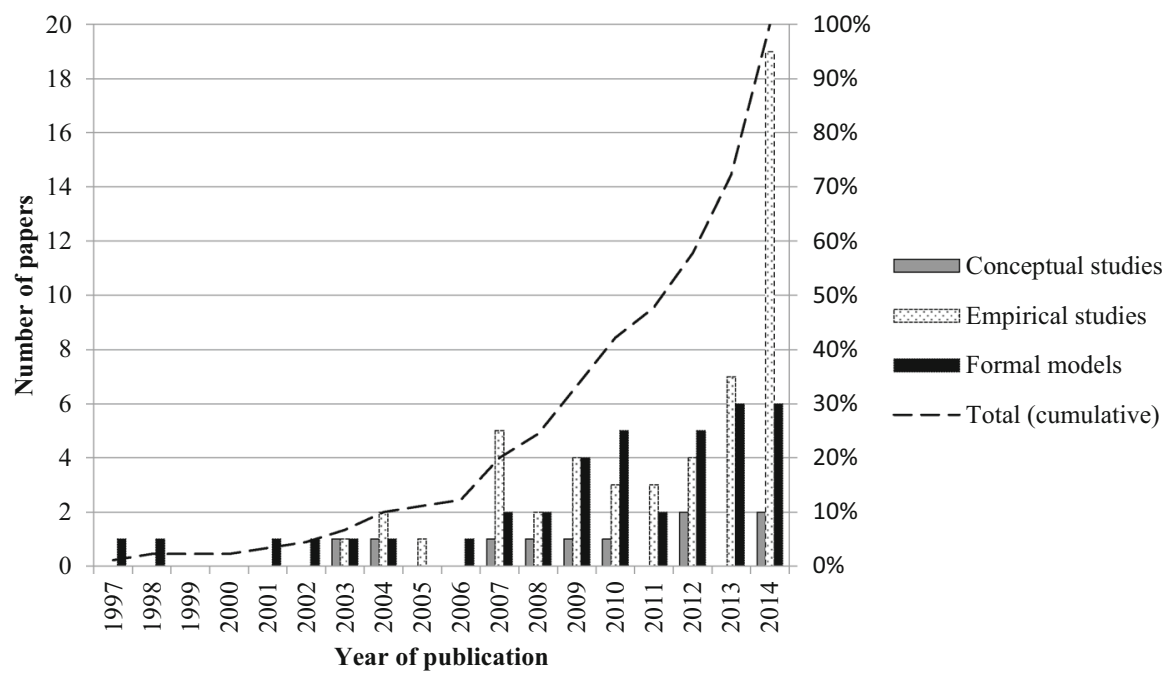

Fig. 1 Distribution of sample papers over time

stakeholder triggers, SSCM performance, and risks are still not thoroughly explored. This is in line with a call for more in-depth empirical research on risk management in SCs (Khan and Burnes 2007). Thus, research in the form of case studies and surveys that support the development of conceptual frameworks and formal models still appears necessary.

\subsubsection{Distribution of sample papers over journals}

The distribution of sample publications over journals (see Table 5) shows a clear split into journals for conceptual and empirical studies (SCMIJ, IJOPM, JSCM) or periodicals for formal modeling (EJOR, IJPR, other journals). Only JCLEPRO 
Table 5 Distribution of sample papers over scientific journals

\begin{tabular}{lllll}
\hline Journal & Conceptual papers & Empirical studies & Formal models & Total \\
\hline JCLEPRO & 5 & 19 & 4 & 28 \\
SCMIJ & 3 & 4 & - & 7 \\
IJOPM & 1 & 4 & - & 5 \\
JSCM & 1 & 2 & - & 3 \\
JOM & - & 4 & - & 4 \\
IJPE & - & 4 & 10 & 14 \\
EJOR & - & - & 5 & 5 \\
IJPR & - & - & 5 & 5 \\
Other journals & - & 4 & 15 & 19 \\
Total & $\mathbf{1 0}$ & $\mathbf{4 1}$ & $\mathbf{3 9}$ & $\mathbf{9 0}$ \\
\hline
\end{tabular}

JCLEPRO Journal of Cleaner Production, SCMIJ Supply Chain Management: An International Journal, IJOPM International Journal of Operations and Production Management, JSCM Journal of Supply Chain Management, JOM Journal of Operations Management, IJPE International Journal of Production Economics, EJOR European Journal of Operational Research, IJPR International Journal of Production Research

features publications from all three research designs, and IJPE is positioned at the interface of empirical and modeling publications. SCMIJ is most prominent for conceptual and empirical studies. IJPR and EJOR are the preferred journals for formal models, which are further distributed over other miscellaneous journals. Special volumes and issues of certain journals are of minor relevance for the selected paper sample. Only the peak of empirical studies in 2014 is partly due to a special volume in IJPE (volume 152, contributing four sample papers) and two special volumes in JCLEPRO (volumes 63 and 85, each contributing two sample papers).

\subsection{Bibliometric analysis}

A bibliometric analysis of the selected sample papers was conducted to identify key publications that triggered related research and to evaluate the degree of connectedness of qualitative and quantitative SSCM research on stakeholder triggers and SSCM risks. According to the number of locally cited articles, the key papers with the highest LCS and LCR are displayed in Table 6.

The most influential literature review on SSCM focuses on both triggers and risks for SSCM (Seuring and Müller 2008b). It is followed by three empirical papers one on green SCM pressures, practices, and performance in China (Zhu et al. 2005), one on sustainable supply management in the automotive industry (Koplin et al. 2007), and the other in the context of the oil, gas, and agricultural biotechnology industries (Matos and Hall 2007). Two formal models on environmental criteria in supply networks (Nagurney and Toyasaki 2003) and for supplier assessment (Handfield et al. 2002) complement those papers that have triggered subsequent research activities, particularly after 2008. Apart from this, recent papers with a high 
Table 6 Ranking of the most influential sample papers

\begin{tabular}{llclr}
\hline Rank & Paper & LCS & Paper & LCR \\
\hline 1 & Seuring and Müller (2008b) & 20 & Seuring and Müller (2008b) & 10 \\
2 & Zhu et al. (2005) & 10 & Miemczyk et al. (2012) & 7 \\
3 & Handfield et al. (2002) & 8 & Beske and Seuring (2014) & 6 \\
& Koplin et al. (2007) & 8 & Foerstl et al. (2014) & 6 \\
4 & Matos and Hall (2007) & 7 & Govindan et al. (2014a) & 5 \\
& Nagurney and Toyasaki (2003) & 7 & Leppelt et al. (2013a) & 5 \\
\hline
\end{tabular}

number of references to other sample papers, i.e., a high LCR score, comprise three conceptual papers (Seuring and Müller 2008b; Miemczyk et al. 2012; Beske and Seuring 2014) and three case studies (Foerstl et al. 2014; Govindan et al. 2014a; Leppelt et al. 2013a).

Correlation analysis of the citation indices shows a significant positive relationship between LCS and the global citation score (GCS), i.e., the articles that are most cited by other sample papers are comparably often cited by other publications not being part of the selected sample listed on Web of Science. Hence, globally important papers are accordingly relevant in the paper sample so that the rigor of the sampling process is supported.

Discernible directions of and mutual stimulations between conceptual and empirical studies on the one hand and formal models on the other can be observed. Thus, a bibliometric analysis is conducted to analyze the citations within the paper sample, i.e., within each cluster and between the two clusters, and to assess the extent to which the two research clusters stimulate each other. The number of citations within each cluster and between the two clusters is counted and, furthermore, the ratio of observed citations and theoretically possible citations is calculated under consideration of the cluster sizes and the paper distribution over time.

The bibliometric coherence between conceptual and empirical papers on the one hand and modeling papers on the other is illustrated in Fig. 2. In each of these two groups of papers, we distinguish between (a) papers that are cited by but do not refer to manuscripts from the other group, (b) papers that refer to but are not cited by manuscripts from the other group, (c) papers that cite and are being cited by manuscripts from the other group, and (d) papers that are not bibliographically linked to manuscripts from the other group. We count the number of observed citations within each and between both groups of papers. Moreover, these observed citations are expressed as the percentage of the numbers of (theoretically possible) citations. The theoretically possible number of citations is approximated by the assumption that a manuscript can cite any paper that is published in an earlier year, but no paper that is published in the same year or in the following years. Related observations that shed light on the coherence of conceptual and empirical research on the one hand and model-based research on the other are summarized and interpreted in the remainder of this subsection. 


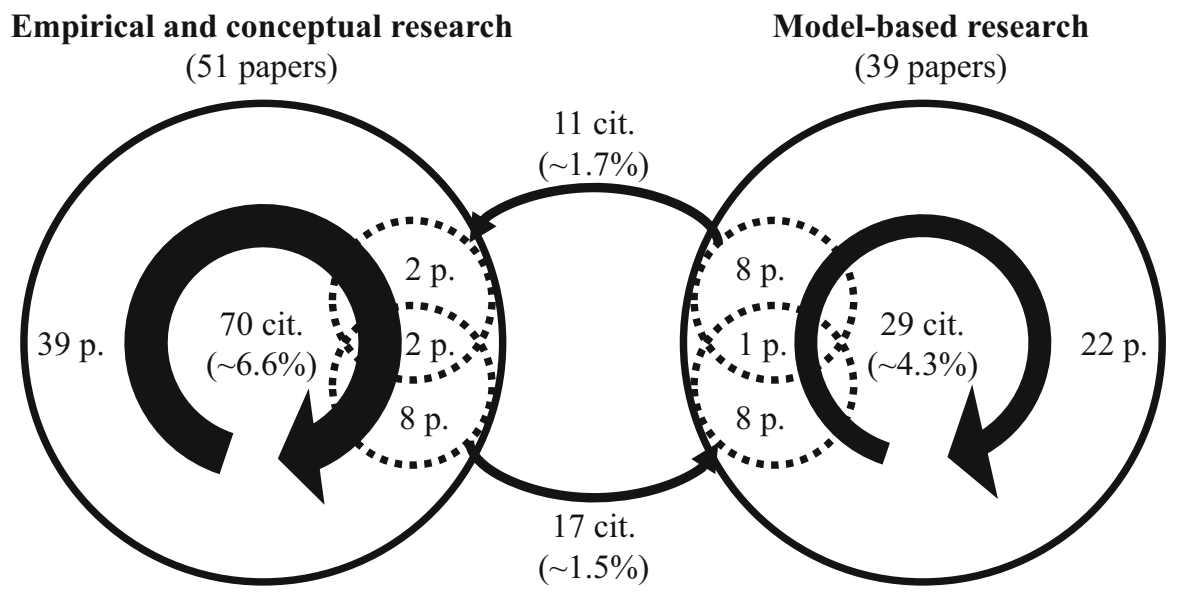

Arrows indicate reference and point towards papers being cited

Fig. 2 Citations within and between the two research clusters

The numbers of citations within each cluster are comparably high. In total, 70 citations (i.e., representing approximately $6.6 \%$ of all possible citations) are observed within the conceptual and empirical research cluster and 29 citations (approximately 4.3\%) are found within the model-based research cluster. Comparably few citations from one research cluster refer to papers from the other cluster. Only 11 citations (approximately 1.7\%) from 9 modeling papers refer to 4 conceptual or empirical studies, and vice versa only 17 citations (i.e., approximately $1.5 \%$ ) from 10 conceptual or empirical studies refer to 9 modeling papers. Only two conceptual/empirical studies (Seuring and Müller 2008b; Zhu et al. 2005) and one modeling paper (Bai and Sarkis 2010) do refer to and are also cited by papers from the other cluster and, thus, represent the core link between the two research clusters. While the literature review by Seuring and Müller (2008b) covers both stakeholder triggers and SSCM risks in their conceptual framework based on the TBL of sustainability, the survey by Zhu et al. (2005) enquires into green SCM pressures, practices, and performance in China. The formal modeling paper by Bai and Sarkis (2010) uses grey system and rough set theory to incorporate the aspects of the TBL of sustainability holistically into supplier selection.

To conclude, these observations illustrate that the link between conceptual frameworks and empirical studies on the one hand and model-based research on the other hand leaves much room for improvement in the area of SSCM. Without strengthening this relationship, it will be difficult to achieve a comprehensive and mature level of research that integrates deductive and inductive approaches and that ranges from theory development to theory testing.

In the remainder of this section, we present the findings of the content analysis. From this content analysis, we develop a conceptual framework for stakeholder influences and risks in SSCM (see Sect. 5) and propose guidelines for future SSCM 
research. These guidelines may help in bridging the gaps and strengthening the relationships between conceptual, empirical, and model-based SSCM research.

\subsection{Content analysis}

Content analysis involves coding dimensions and categories, as outlined in Sect. 3.3. It comprises the findings for actors, levels, and functions of analysis, industry focus, TBL orientation as well as stakeholder triggers and risks for SSCM.

\subsubsection{Actors, levels, and functions of analysis}

The focused actors and levels of analysis are shown in Tables 7 and 8. Principally, manufacturers are the focus of empirical studies and formal models, whereas conceptual papers do not concentrate on single actors. Conceptual ( 9 papers) and empirical studies (18 papers) exhibit a stronger tendency to include multiple actors of analysis compared to formal models (14 papers), which put a narrower focus to build the model on a decent scale of complexity by focusing on single actors (18 papers on manufacturers, 5 papers on carriers, 2 papers on retailers). For empirical studies and formal models, however, the manufacturer is emphasized. Distributors and warehousing are not taken into consideration at all. Hence, it can be questioned why inventory-related SSCM risks remain unconsidered to date and whether inventory management matters with respect to SSCM triggers. The fact that thirdparty logistics providers currently play a central role in SCs implies a need to increase attention toward the related underrepresented SC actors.

While most conceptual frameworks consider multiple SC actors, only Cousins et al. (2004) concentrate on the focal company by exploring the risk of environmentrelated supplier initiatives. Four case-based studies (Quak and de Koster 2007, 2009; Andersen and Skjoett-Larsen 2009; Chkanikova and Lehner 2014) empirically elaborate on retailers and take into account all three TBL factors. Quak and de Koster (2007, 2009) formally model governmental pressures arising from local authorities that restrict delivery time windows. Retailers are mostly empirically analyzed with regard to governmental stakeholder influences, but rarely in conjunction with environmental or social risks (Andersen and SkjoettLarsen 2009; Quak and de Koster 2007, 2009). Andersen and Skjoett-Larsen (2009) take into account stakeholder influences from government, customers, and other stakeholder groups. Chkanikova and Lehner (2014) study economic and social risks

Table 7 Primary actor of analysis

\begin{tabular}{lcccc}
\hline Primary actor of analysis & Conceptual studies & Empirical studies & Formal models & Total \\
\hline Manufacturer & 1 & 19 & 18 & 38 \\
Carrier & - & - & 5 & 5 \\
Retailer & - & 4 & 2 & 6 \\
Multiple & 9 & 18 & 14 & 41 \\
Total & $\mathbf{1 0}$ & $\mathbf{4 1}$ & $\mathbf{3 9}$ & $\mathbf{9 0}$ \\
\hline
\end{tabular}


Table 8 Level of analysis

\begin{tabular}{lcccc}
\hline Level of analysis & Conceptual studies & Empirical studies & Formal models & Total \\
\hline Dyad & 2 & 3 & 12 & 17 \\
Chain & 4 & 33 & 5 & 42 \\
Network & 1 & 2 & 22 & 25 \\
Other & 3 & 3 & - & 6 \\
Total & $\mathbf{1 0}$ & $\mathbf{4 1}$ & $\mathbf{3 9}$ & $\mathbf{9 0}$ \\
\hline
\end{tabular}

in context of certification of organic brands in food retailing and find that third-party certification schemes are highly relevant for food markets to reduce transaction costs and liability risks.

Only one formal model considers a retailer. Rosic and Jammernegg (2013) employ a newsvendor approach to assess the economic and environmental performance in dyads with dual sourcing options. Besides financial and environmental risks, the model includes emission taxes and, thus, reflects the environmental pressures of legal authorities. The authors find that emission trading is preferable compared to emission taxes to improve environmental aspects while maintaining economic performance.

The five carrier-related formal models are settled in the context of transportation planning. Four of the models exclusively look at environmental aspects like greenhouse gas emissions in context of slow steaming (Bektas and Laporte 2011; Corbett et al. 2009; Fagerholt et al. 2010) or modal shifts (Eng-Larsson and Norrman 2014), and one model considers noise as social aspect of airports that act as multimodal transport nodes (Janic 2011). Sustainability-related modeling approaches are based on the vehicle routing problem (VRP). In contrast, other traditional transportation models, such as the travelling salesman problem (TSP) or Hitchcock-Koopmans transportation problem, remain unconsidered in related model development. This observation is surprising, as these traditional models are relevant for research on conventional transportation that focuses on economic criteria only. However, adding sustainability criteria would be possible, e.g., by considering solution approaches for the multi-objective Hitchcock-Koopmans problem developed by Aneja and Nair (1979).

The preferred level of analysis (see Table 8 ) for conceptual and empirical studies is the chain ( 37 papers) extending beyond a mere two-party dyad level (5 papers). In contrast, more than half of the examined formal models choose a network focus that integrates several SC actors and locations in supply and distribution networks (22 papers), and roughly one-third departs from a dyadic level of analysis (12 papers) in the context of sourcing.

In addition to the buyer-supplier dyadic relationship, conceptual and empirical studies extend the scope of analysis to the customer side or sub-suppliers as an additional stage in the SC. Even if the focus of many case studies is on sourcing, the downstream SC actors are also considered. Taking into account the network level, one conceptual paper (Miemczyk et al. 2012) reviews definitions and measures for sustainable purchasing on dyads, chain, and network levels; one case study (Rizzi 
et al. 2014) focuses on green networks of small- and medium-sized enterprises; and one survey (Severo et al. 2014) assesses networks in the Brazilian metal-mechanic industry.

Six papers are not assigned to dyad, chain, or network levels of analysis, as their scope of analysis either extends to industrial and macro-economic factors (Adams and Ghaly 2007; Lorek and Spangenberg 2014; Michaelis 2003; Moore and Ausley 2004) or narrows to the firm focus (McDonald and Young 2012; Moore and Manring 2009). Hence, no clear classification was possible for these papers even though they principally address inter-organizational SSCM contexts.

The distribution of papers according to the functions of analysis is displayed in Table 9. Most papers consider SCM as an overall planning approach that aims at determining the strategic directions toward SSCM across different business functions. In contrast to the category "SCM", the remaining categories focus on specific functional areas that predominantly embody tactical or operational contexts with medium- or short-term implications. Sourcing contexts, which nonetheless may also have a strategic impact, are considered across the different research designs and address supplier selection and evaluation as well as the operation of supplier-buyer relationships and supplier development approaches. Three conceptual papers (Cousins et al. 2004; Pagell et al. 2010; Miemczyk et al. 2012) strive for a general conceptualization of sustainable sourcing, while empirical studies and formal models aim at the more concrete application of sustainability approaches in sourcing. In total, eight formal models elaborate on supplier selection (Noci 1997; Bai and Sarkis 2010) and assessment (Handfield et al. 2002; Lu et al. 2007) or supplier-buyer-relationship operations (Ni and Li 2012; Corbett and DeCroix 2001; Choi 2013; Chen and Slotnick 2014). Most empirical studies on sourcing elaborate on sourcing risks (Koplin et al. 2007; Christopher et al. 2011) or drivers and factors of sustainable sourcing (Foerstl et al. 2014; Grimm et al. 2014). In contrast to conceptual and formal models, empirical studies also cover aspects of public procurement (Rizzi et al. 2014).

Only four papers focus on the production function. They deal with toxicity in the textile industry (Moore and Ausley 2004), sustainability in the coffee industry

Table 9 Function of analysis

\begin{tabular}{lllrr}
\hline Function of analysis & Conceptual studies & Empirical studies & Formal models & Total \\
\hline SCM & 6 & 16 & 12 & 34 \\
Sourcing & 3 & 8 & 8 & 19 \\
Envir./CSR mgmt & 1 & 5 & - & 6 \\
Logistics & - & 3 & 7 & 10 \\
Network design & - & - & 6 & 6 \\
Production & - & 3 & 1 & 4 \\
Other & - & $6^{\text {a }}$ & $5^{\text {b }}$ & 11 \\
Total & $\mathbf{1 0}$ & $\mathbf{4 1}$ & $\mathbf{3 9}$ & $\mathbf{9 0}$ \\
\hline
\end{tabular}

${ }^{a}$ Materials management (1 paper), product development (3), standards/certifications (2)

${ }^{\mathrm{b}}$ Pricing (2 papers), technology/IT (3) 
(Adams and Ghaly 2007), cleaner production in the Brazilian metal industry (Severo et al. 2014), or present a generic model to assess economic, environmental, and energy interactions (Oliveira and Henggeler-Antunes 2004). The scarcity of production-related papers is not surprising, as an inter-organizational focus is central to our study. The remaining empirical studies are distributed over environmental and corporate social responsibility (CSR) management, standardization, and certification, which altogether points to strategic decisions. In contrast, formal models preferably cover logistics, network design, production as well as pricing and technology-related contexts on a tactical or operational level.

\subsubsection{Industry focus}

The findings regarding the industry foci are presented in Table 10. They suggest that conceptual and empirical studies explore stakeholder triggers and risks for SSCM in various industry contexts. The food and beverages sector ( 8 papers), the apparel/textile industry ( 4 papers), the metal/mining industries ( 5 papers) and the automotive sector ( 3 papers) are the main industries concerned. Formal models less often choose to apply models to certain industry contexts (17 papers undisclosed/generic), whereas models for apparel/textiles production, metal/mining and electronics industries, and the energy sector (9 papers) as well as for the transportation sector (6 papers) are prominent. In addition, many formal models use generic numerical examples rather than empirical data for illustrative examples. Models without a specific industry focus are mainly based on such numerical examples (almost half of the modeling papers).

Food and beverages are obviously prominent fields of SSCM research. Related sample papers deal with transparency and accountability in seafood industries (Iles 2007), the coffee industry (Adams and Ghaly 2007), and the sustainable SC performance of Greek food SCs involving several micro-, small-, and medium-sized firms (Bourlakis et al. 2014). Eco-brands for food products sold in retail are

Table 10 Industry focus

\begin{tabular}{lcccc}
\hline Industry focus & Conceptual studies & Empirical studies & Formal models & Total \\
\hline Apparel/textile & - & 1 & 3 & 4 \\
Automotive & - & 2 & 1 & 3 \\
Chem./pharmaceutical & - & 2 & 1 & 3 \\
Food/beverages & 1 & 7 & - & 8 \\
Metal/mining & - & 3 & 2 & 5 \\
Transportation & - & - & 6 & 6 \\
Other & - & $6^{\mathrm{a}}$ & $7^{\mathrm{b}}$ & 13 \\
Multiple & - & 13 & 2 & 15 \\
Undisclosed/generic & 9 & 7 & 17 & 33 \\
Total & $\mathbf{1 0}$ & $\mathbf{4 1}$ & $\mathbf{3 9}$ & $\mathbf{9 0}$ \\
\hline
\end{tabular}

\footnotetext{
${ }^{a}$ Agriculture (1 paper), engineering (1), furniture (1), public procurement (1), tourism (2)

b Agriculture (1 paper), biofuel (1), electronics (2), energy (2), retail (1)
} 
examined by Chkanikova and Lehner (2014). Pressures, incentives as well as drivers and barriers for environmental management (Grekova et al. 2014; Massoud et al. 2010) and particularly sub-supplier management (Grimm et al. 2014) are further topics observed apart from sustainable food quality and safety (Ting et al. 2014). It is striking that the paper sample does not contain modeling papers on the food industry, as formal models and analytic methods are adequate to analyze sustainability in food SCs (Akkerman et al. 2010).

Surprisingly, some sectors are rarely studied. The automotive industry is an economically relevant sector with complex integrated supplier relationships. Process industries, like chemical and pharmaceutical or oil and gas production, involve hazardous goods and enormous environmental impact in cases of accidents, while the apparel and textile industries additionally involve social issues like decent working conditions.

One way to mutually stimulate empirical and model-based research might target transportation models for food and beverages SCs. These SCs are characterized by distinct product quality issues due to perishability. Current research activities and transnational projects substantiate the growing importance of sustainable food logistics. Carrier-related models, as described in Sect. 4.3.1, raise exemplary issues like the pollution routing problem, maritime logistics and slow-steaming as well as multi-modal transport systems, although not all of these SSCM practices may be applicable for food logistics. In this context, future research should address these goal conflicts between quality, speed, cost, and emissions. In addition, the risks of and triggers for distinct SSCM practices should be taken into account by formal models.

There is overlap between empirical studies and models with regard to the automotive and the metal/mining industries. Empirical automotive papers elaborate on the impact of SCM practices on sustainability (Govindan et al. 2014a) and sustainable supplier management (Koplin et al. 2007), while the only formal model in this industrial context establishes a green supplier assessment scheme (Noci 1997). Empirical metal/mining papers concentrate on sustainable production (Severo et al. 2014), risk management for sustainable design in the minerals industry (McLellan and Corder 2013), and cross-sector collaboration for CSR best practice (McDonald and Young 2012), while models are developed to assess the environmental impact analytically (Ferretti et al. 2007) and to plan sustainable network design using goal programming (Ramudhin et al. 2010). The striking difference between empirical and modeling research is that the automotive and metal/mining related models only address triggers, particularly governmental pressures, while the empirical studies additionally include at least economic risks. Hence, models in these industry contexts should also integrate environmental and social risks in SCM.

\subsubsection{Dimensions of the TBL of sustainability}

The number of publications that address the TBL of sustainability is shown in Fig. 3. Most formal models (24 papers) concentrate on the interplay of economicenvironmental aspects, and one-third integrate the sustainability dimensions of the 
Fig. 3 Dimension of the TBL of sustainability

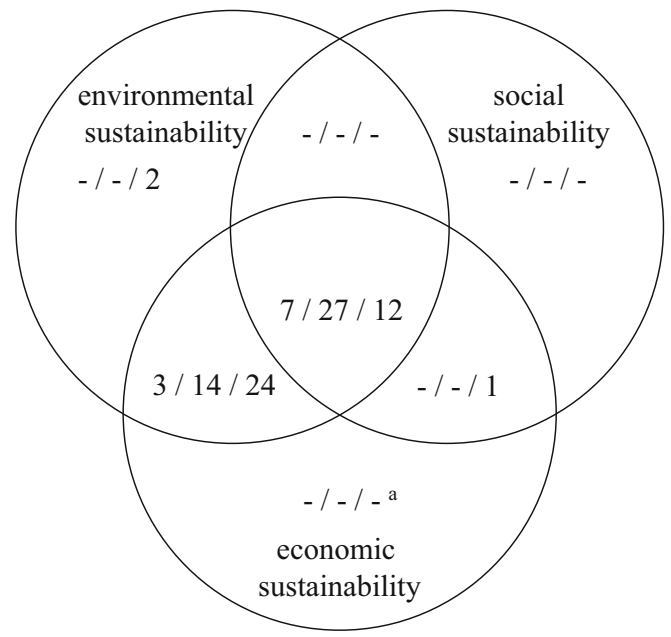

Legend: conceptual studies / empirical studies / formal models

a Purely economic studies are not in focus

TBL holistically (12 papers). In contrast, two-thirds of conceptual and empirical studies consider all three dimensions of the TBL of sustainability. A focus on the social dimension is underrepresented for all research streams, but particularly for formal models.

As expected, many papers focus on economic-environmental issues. However, surprisingly, many holistic papers are identified, three quarters of which were published within the last 5 years. More than every second conceptual and empirical paper and every third formal model integrate the TBL of sustainability holistically. This is in contrast to the clear focus of quantitative SSCM models on the economicenvironmental interplay (see, e.g., Brandenburg et al. 2014) and points toward a higher level of maturity in SSCM research that integrates social sustainability aspects into economic-environmental studies. There is no clear tendency for holistic TBL papers to focus on either or both SSCM triggers and risks or specific industries. For instance, all four empirical papers that consider retailers as actors of analysis (see Sect. 4.3.1) address all three TBL dimensions.

As a result of the data collection for the present study, no purely social and only two purely environmental papers are published in the selected SCM context and related journals. Handfield et al. (2002) and Lu et al. (2007) exclusively focus on environmental principles for green supplier evaluation, both using an analytic hierarchy process (AHP) model. One socio-economic model ( $\mathrm{Ni}$ and $\mathrm{Li} 2012$ ) is formulated as a game-theoretical approach to analyze social responsibility on a dyadic level.

\subsubsection{Overview of stakeholder triggers and SSCM risks across the paper sample}

To give a preliminary overview of the relative importance of SSCM triggers and risks addressed in the paper sample, Table 11 shows the numbers of studies that only concentrate on triggers or only elaborate on risks and those articles that cover 
Table 11 Integration of stakeholder triggers and SSCM risks

\begin{tabular}{lllll}
\hline & Only triggers & Triggers and risks & Only risks & Total \\
\hline Conceptual & 4 & 3 & 3 & 10 \\
Empirical & 15 & 15 & 11 & 41 \\
Formal models & 19 & 11 & 9 & 39 \\
Total & $\mathbf{3 8}(\mathbf{4 2 \%})$ & $\mathbf{2 9}(\mathbf{3 2 \%})$ & $\mathbf{2 3}(\mathbf{2 6 \% )}$ & $\mathbf{9 0}(\mathbf{1 0 0 \%})$ \\
\hline
\end{tabular}

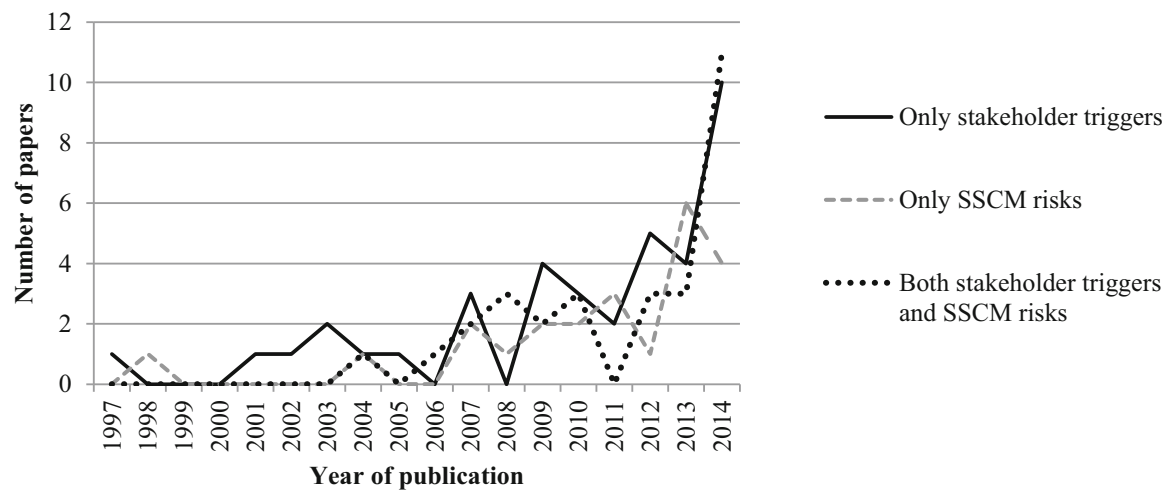

Fig. 4 Distribution of sample papers over publication years focusing on only stakeholder triggers, only SSCM risks, or both dimensions

both dimensions of analysis. Nearly every second paper omits SSCM risks, while about three quarters of all studies include SSCM triggers. Almost one-third of the sample papers include both triggers and risks. With regard to the research design of the studies, an equal share of empirical studies and formal models is obtained. Considerably fewer conceptual papers are collected.

Figure 4 displays the distribution of sample papers over publication years and differentiates between articles that only focus on either stakeholder triggers or SSCM risks and articles that integrate both dimensions. It illustrates that research on stakeholder triggers and risks for SSCM is of increasing interest. Already from 2007 onward, the number of publications per year that integrate both stakeholder triggers and risks for SSCM started to increase. In particular, the number of studies that include both dimensions has grown in the last two years of the reviewed time horizon. This indicates growing interest in the interplay of stakeholder influences and risks for SSCM performance.

\subsubsection{Stakeholder triggers for SSCM}

The frequencies of the analytical categories in the structural dimension of stakeholder triggers are given in Table 12, while Table 13 provides a more indepth illustration of the various groups of primary and secondary stakeholders. Our study analyzes pressures and incentives by which stakeholders aim at fostering the 
Table 12 Stakeholder triggers for SSCM

\begin{tabular}{lllc}
\hline Stakeholder triggers & Conceptual studies & Empirical studies & Formal models \\
\hline Focused (at least one) & 4 & 22 & 26 \\
All factors & 3 & 8 & 4 \\
None of the factors & 3 & 11 & 9 \\
Customers $^{\mathrm{a}}$ & 5 & 17 & 12 \\
Government $^{\mathrm{a}}$ & 4 & 18 & 23 \\
Other stakeholders $^{\mathrm{a}}$ & 6 & 22 & 4 \\
Thereof other primary $^{\mathrm{a}}$ & 1 & 11 & 2 \\
Thereof other secondary $^{\mathrm{a}}$ & 6 & 22 & 4 \\
\hline
\end{tabular}

${ }^{a}$ Multiple classification possible

Table 13 Detailed distinction between primary and secondary stakeholder triggers for SSCM

\begin{tabular}{|c|c|c|c|}
\hline Stakeholder triggers & Conceptual studies & Empirical studies & Formal models \\
\hline \multicolumn{4}{|l|}{ Primary stakeholders ${ }^{\mathrm{a}}$} \\
\hline Customers & 5 & 17 & 12 \\
\hline Suppliers & 1 & 8 & 1 \\
\hline Employees & - & 5 & - \\
\hline Shareholders & - & 2 & - \\
\hline Top management & - & 2 & 1 \\
\hline \multicolumn{4}{|l|}{ Secondary stakeholders ${ }^{\mathrm{a}}$} \\
\hline Government & 4 & 18 & 23 \\
\hline NGOs & 4 & 12 & - \\
\hline Competitors & 2 & 7 & 1 \\
\hline Local community & - & 3 & 1 \\
\hline Media & - & 3 & - \\
\hline Trade unions & - & 1 & - \\
\hline Investors & 1 & 3 & 1 \\
\hline Wider public & 1 & 5 & 2 \\
\hline Unspecified/generic & 1 & 8 & 2 \\
\hline
\end{tabular}

${ }^{a}$ Multiple classification possible

sustainable management of SCs. However, a clear differentiation between a trigger being pressure or rather an incentive is mostly dependent on the context. While subsidies are usually incentivizing triggers for firms to, e.g., invest in environmental technology, taxes and fines are typically pressuring triggers. Considering different stakeholder triggers for SSCM, conceptual and empirical studies mainly concentrate on customers and other stakeholders or even attempt to integrate all factors (11 papers) in a greater proportion than formal models that hardly integrate all factors (4 papers). Thus, conceptual and empirical studies feature a stronger customer orientation than formal models, and empirical studies try to holistically examine various kinds of stakeholder triggers. In contrast, formal models preferably integrate 
governmental pressures and incentives. This may suggest that governmental triggers, e.g., in the form of carbon taxes or emission limits, can be operationalized more easily than customer and other stakeholder expectations that are less tangible and sometimes fuzzy, and thus more difficult to measure. On the one hand, this is surprising because these governmental triggers affect companies first on a strategic management level, while formal models in operations and SC management typically tend to focus on tactical and operational decisions. This is an indication that formal modeling in the SSCM context is equally important on a strategic decision-making level, e.g., using multi-criteria decision-making approaches for the evaluation and selection of alternatives.

If other stakeholders are considered, then secondary stakeholders are always included while primary stakeholders are dealt with in selected cases (see Tab. 13). Other primary stakeholders predominantly include suppliers and employees, but shareholders and top management are also taken into account in a few cases. Other secondary stakeholders comprise NGOs and competitors, whereas local communities, the media, trade unions, and investors are seldom considered.

Conceptual literature outlines the management of pressure groups (Beske and Seuring 2014) as a key element in SSCM. Sample case studies likewise focus on action groups and investors (Dam and Petkova 2014), NGO pressure (McDonald and Young 2012; Geibler 2013; Foerstl et al. 2014), or social pressure in general terms (McDonald and Young 2012). Further, a considerable share of formal models concentrates on governmental and other regulatory triggers in the form of emission taxes or quotas (Dou and Sarkis 2010; Walther et al. 2012; Rosic and Jammernegg 2013).

Only four models concentrate on other stakeholder triggers. Noci (1997) operationalizes the type of relationships between the focused supplier and its stakeholders in an AHP model, while Dou and Sarkis (2010) include stakeholder engagement using the analytic network process (ANP). Chen and Slotnick (2014) employ game theory and include the public discovery probability of unethical procurement activities as one factor determining the decision for information disclosure. Here, the market response to information disclosure as well as costs and market share are taken into account. Applying interpretative structural modeling to identify enablers for SSCM adoption, Diabat et al. (2014) comprise global competition pressures, investor pressures, community and public pressures, and internal pressure on managers.

In contrast, a huge share of conceptual and empirical papers integrated various stakeholders in addition to the regulatory framework and customers. For these papers, multiple stakeholder influences-particularly customer pressures-are reflected by a considerable number of papers for the context of food and beverage industries (also see Sect. 4.3.1). Influences of other stakeholders, e.g., NGOs, the media, investors, trade unions, or the local community, could be reflected in formal models. However, formal modeling of multiple stakeholders is complicated by the need to define appropriate scales of measurement for stakeholder triggers. Suitable modeling approaches that enable the integration of various stakeholders have to be chosen to ensure that the model complexity does not complicate solvability and prevent meaningful results. 


\subsubsection{SCM risks}

Considering conventional SC risks, which still apply in a sustainable SC, the sample paper is coded according to the four risk factors formulated by Tang (2006), as displayed in Table 14. Supply risks include general supplier risk (Foerstl et al. 2014), the risk of supplier non-conformance (Wu and Pagell 2011), and the certification to mitigate supply risks (Beske and Seuring 2014). Demand risks are mentioned as the risk of unsold products and services (Adriana 2009), customer sustainability demands (Foerstl et al. 2014; Hartmann and Moeller 2014), the risk for increased regulation and diminished reputation (Wu and Pagell 2011), or reputational risk (Roehrich et al. 2014). Product risk is analyzed in terms of quality risk (Ting et al. 2014). Information risks are relevant in the form of information asymmetries (Beske and Seuring 2014), the risk of fragmentation of certification standards and incompatible certification systems (Geibler 2013), the risk of disclosure of a company's unethical sourcing activities (Chen and Slotnick 2014), and risk attitudes related to information sharing (Kainuma and Tawara 2006). On the contrary, it is remarkable that information risks are widely neglected by all research designs. Principally, information sharing goes beyond the mere communication of order quantities so that the resulting low numbers are surprising. Only one formal model (Kainuma and Tawara 2006) considers different risk attitudes in which information sharing with regard to supplier lead time and demand as well as the product is included.

To conclude, supply risks relate to compliance, conformance, and the certification of suppliers. Demand risks relate to unsold products, growing sustainabilityrelated requirements or regulations, and to reputation loss. Product risks concern product quality and certification standards. Information risks are addressed in relation to certification systems, information asymmetries, and the disclosure of unsustainable behavior.

\subsubsection{SSCM risks}

Beyond conventional SC risks, TBL-related risk factors are considered to complement the economic viewpoint of SC risk management with environmental

Table 14 Supply chain risk management

\begin{tabular}{llcc}
\hline SC risks (Tang 2006) & Conceptual studies & Empirical studies & Formal models \\
\hline Supply risk $^{\mathrm{a}}$ & 5 & 11 & 9 \\
Demand risk $^{\mathrm{a}}$ & 2 & 13 & 7 \\
Product risk $^{\mathrm{a}}$ & 1 & 8 & 7 \\
Information risk $^{\mathrm{a}}$ & 1 & 2 & 2 \\
Focused (at least one) & 6 & 22 & 16 \\
All factors & - & - & 1 \\
None & 4 & 17 & 22 \\
\hline
\end{tabular}

${ }^{a}$ Multiple classification possible 
and social aspects (see Fig. 5). Conceptual and empirical studies consider economic $\mathrm{SC}$ risk management in a marginally greater proportion than formal models, while purely social or environmental risks are seldom emphasized in any of these methods. Complexity aspects help to explain the observation that comparably few modeling papers consider risk issues. Risks are usually modeled by stochastic or scenario-based approaches, which are more complex than purely deterministic models. In contrast, the complexity increase in conceptual or empirical research is limited even when risk factors are taken into consideration. Conceptual and empirical studies represent a remarkable share with a purely economic risk management focus (17 papers) besides formal models with a slightly lower share (ten papers). Both research streams manage to integrate all three dimensions of the TBL of sustainability to a similar extent. However, a focused analysis of economic risks prevails over environmental and social risks, and the assessment of mutual interfaces is scarce.

Formal models integrate economic and environmental aspects and widely neglect the social dimension. In contrast, conceptual and empirical studies also emphasize socio-economic risks. This indicates that conceptual and empirical research strives to relate social risks to economic performance, while it seems hard to operationalize and measure them in formal models.

Two conceptual papers study all three TBL risk dimensions with regard to SSCM (Seuring and Müller 2008b) and supplier initiatives in particular (Cousins et al. 2004). Five case studies (Matos and Hall 2007; Adriana 2009; Reuter et al. 2010; Christopher et al. 2011; Govindan et al. 2014a) and one survey (Hartmann and Moeller 2014) cover TBL risks holistically. Moreover, seven formal models embrace economic, environmental, and social risks for supply network planning (Cruz 2008, 2009, 2013a, b; Cruz and Matsypura 2009), offshoring decisions (Dou and Sarkis 2010), and renewable energy projects (Georgopoulou et al. 1998).

Fig. 5 TBL risks in SSCM

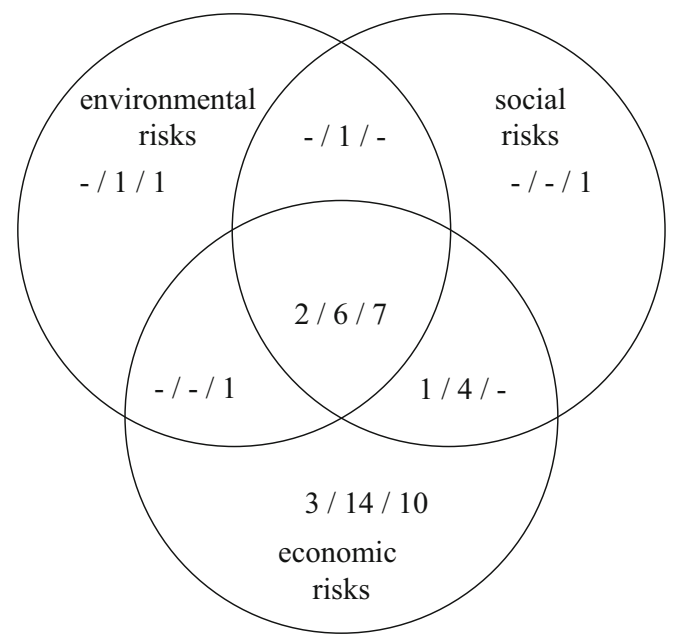

Legend: conceptual studies / empirical studies / formal models Note that risks are not addressed or modeled by: 4 / 15 / 19 
A purely environmental risk focus is chosen by Massoud et al. (2010), who consider risks from pesticide residues in solid waste and assess the regulatory, infrastructural, and organizational conditions to improve sustainable food SCs in Lebanon. Similarly, the avoidance of hazardous materials and greenhouse gases is addressed in an AHP model for green supplier evaluation (Lu et al. 2007).

Purely social risks are indirectly emphasized by addressing self-power generation as a community priority for the security of supply, employment, and environment (Oliveira and Henggeler Antunes 2004). Socio-environmental risks include the risk that organizations use materials perceived to be sustainable in unsustainable ways or that materials perceived to be unsustainable could be used differently in a sustainable manner (Lindahl et al. 2014). At the intersection of economic and social risks, Miemczyk et al. (2012) concentrate on the risk elements of sustainability that comprise accidents or risks to reputation, of non-compliance, and of sourcing. The other four empirical studies on socio-economic risks consider health and safety, social risks, and misconduct in general terms.

Regarding industry-specific sustainability risks, no discernible picture could be obtained from the analyzed paper sample. For the preponderant economic risk category, supply and reputation risks are often addressed across different industry sectors. However, industry-specific environmental and social risks are hardly covered or only proposed in very general terms, e.g., as adverse social and environmental impacts (McLellan and Corder 2013). Only few papers specify sustainability-related risks according to the industry context. For the example of food supply chains, environmental risks, e.g., pesticide residues in solid waste (Massoud et al. 2010), or social risks, e.g., health and human risks (Grimm et al. 2014), are specified. Other industry sectors that are studied in the sample papers show no specific environmental and social risk categorization. The prevailing dominance of typical economic risks and the lack of differentiated environmental and social risks point to future research potentials.

\subsubsection{Operationalization of SSCM risks}

The findings from the content analysis reflect the nature of conceptual, empirical, and formal modeling papers with regard to the research approaches to SSCM risks. The similarities and differences are illustrated in Fig. 6, which is inductively derived in the course of the content analysis to shed light on approaches to SSCM risk research. While the approach to risk management differs, the causes and implications are similarly comprehended by the two research clusters. Regarding the approach to risk management, conceptual and empirical studies focus on the identification and systematization of SSCM risks so that risk management processes can be defined for risk mitigation. The distinction of uncertainty and risks is central to a wide range of definitions because the probability of a certain event and the magnitude of its impact must be estimated. Formal models then aim at the quantification and measurement of risks using scenario approaches, sensitivity analyses, and utility functions that represent different risk attitudes.

Most formal models do not aim to measure risks themselves, but rather to integrate quantifiable risk factors into the formalized decision-making approach. 


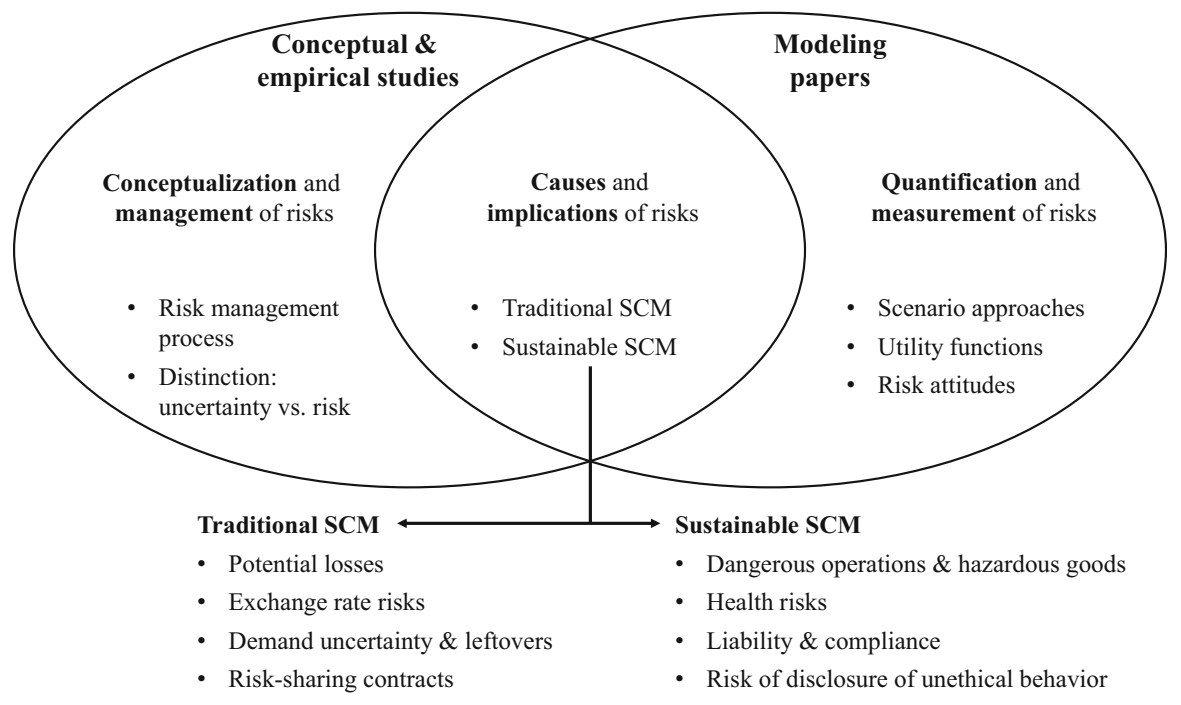

Fig. 6 Similarities and differences regarding risk approaches

Although the determination and definition of risk categories are elaborated by conceptual and empirical studies, the relative importance of risk factors can, for instance, be assessed using formal models like the AHP (see, e.g., Govindan et al. 2014 b). Out of 20 models that integrate SSCM risks, nine stochastic models (seven descriptive-stochastic, two normative-stochastic) are detected. In addition, 11 deterministic models (nine normative-deterministic, two descriptive-deterministic) include SSCM risks. The decision makers that are addressed by formal models are mostly corporate actors. For instance, in the context of supplier evaluation and selection, Bai and Sarkis (2010) use rough set methodology and include four company decision-makers from operations, finance, purchasing, and environmental management departments. These decision makers can also be seen as the internal stakeholders that mediate the pressures and incentives for SSCM from external stakeholders. Other model applications in focal companies concern offshoring decisions (Dou and Sarkis 2010), whereas some macroscopic models also target local authorities or regional governments as decision-makers (e.g., Georgopoulou et al. 1998).

\section{Conceptual development}

In this section, we summarize the findings in comparison to existing research. We then propose a conceptual framework for SSCM risks and stakeholder influences.

\subsection{Summarized findings}

The review of conceptual, empirical, and model-based literature on stakeholder influences and risks in SSCM leads to various insights. The descriptive analysis 
illustrates that this research area evolves and strongly grows and, thus, merits further scientific awareness. Quantitative and qualitative analyses as well as empirical studies and theoretical contributions are in balance.

The content analysis of related literature reveals commonalities of and differences between conceptual frameworks, empirical studies, and formal models. The most common foci regarding all structural dimensions of the content analysis are shown in Table 15. Particularities of each method cluster can be observed when elaborating on the analyzed SC actor and level of analysis, and the considered industry context. Moreover, conceptual and empirical works are distinguished from model-based papers with regard to the reflected TBL dimension of sustainability, the focused stakeholder groups, and the risk categories. In all three method clusters, economic risks prevail while socio-environmental risk facets are less often considered and, hence, leave much room for further analyses. In this regard, each method cluster can be stimulated by different foci taken and further insights gained by the application of other research designs.

The bibliometric analysis illustrates that the group of conceptual and empirical studies is hardly linked to the cluster of formal models while, in contrast, each of these subsamples shows a comparably strong coherence. Only very few publications represent the core interface bridging the gap between the two methodological areas. Hence, the mutual stimuli between and lines of thought across different research methods need to be strengthened to fully exploit the potential of combining inductive and deductive research.

In sum, the study at hand illustrates developments and directions of research on stakeholder influences and risks in SSCM. Similarities and particularities of related conceptual, empirical, and model-based studies reveal the core constructs of this research area based on which a conceptual framework is developed and presented in the next sub-section.

\subsection{Conceptual framework of stakeholder triggers and risks in SSCM}

The sustainable performance of an SC is influenced by stakeholder triggers and sustainability-related risks, as exemplified in a conceptual framework (see Fig. 7).

Table 15 Most common foci regarding all structural dimensions of the content analysis for conceptual, empirical, and formal modeling research

\begin{tabular}{|c|c|c|c|}
\hline & Conceptual papers & Empirical studies & Formal models \\
\hline Actor & Multiple actors & Manufacturer, retailer & Manufacturer, carrier \\
\hline Level & Chain & & Network, dyad \\
\hline Industry & None focused & Food/beverages & Transportation \\
\hline Sustainability & \multicolumn{2}{|c|}{ TBL often holistically addressed } & $\begin{array}{l}\text { Economic-environmental } \\
\text { focus }\end{array}$ \\
\hline Stakeholder influences & Multiple stakeholders & Customers, other & Regulatory triggers \\
\hline SCM risks & $\begin{array}{l}\text { Supply, demand, partic } \\
\text { risks }\end{array}$ & cularly reputational & Operational risks \\
\hline $\mathrm{SSCM}$ risks & \multicolumn{3}{|c|}{ Economic risks prevail, complemented by environmental and social risks } \\
\hline
\end{tabular}




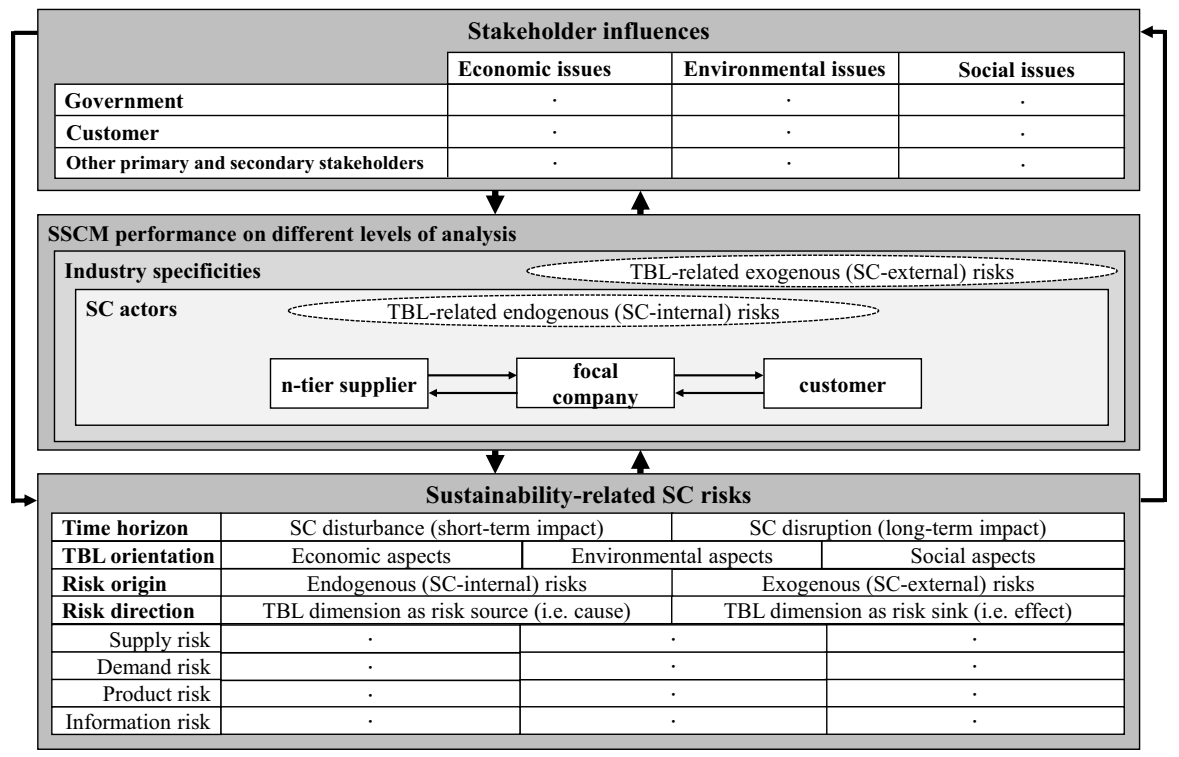

Fig. 7 Conceptual framework of stakeholder influences and risks in SSCM

This framework is based on the core elements identified in the literature review at hand. In addition, it integrates constructs and coherences that are conceptualized in risk management frameworks for traditional SCM, as developed by Tang (2006), Rao and Goldsby (2009), Pfohl et al. (2010), and Heckmann et al. (2015). In this way, the framework not only combines the structural dimensions of the content analysis, but it also includes the main variables and their relationships. The hierarchy of the different constructs is based on the observed frequencies of occurrence (Holweg and van Donk 2009). The framework development is thus based on abductive reasoning, i.e., the combination of deductive and inductive approaches (Spens and Kovács 2006). Hence, the conceptual framework integrates and extends extant theoretical approaches so that the core factors of a theoretical framework are fulfilled (Whetten 1989). In this way, this framework provides an overarching approach for research and practice. Below, we justify the selection of framework elements and the framework structure.

Governments, customers, and other stakeholders address economic, environmental, and social issues that affect SC activities and related risks. These issues are related to whole industries or specific companies and their SCs. The content analysis of stakeholder categories (see Tables 12 and 13) shows that all three main categories (governmental, customer, and other stakeholder influences) are equally important and none should be neglected. From Table 7, we infer that the focal company (manufacturer $42.2 \%$ ) is the dominant SC actor, while other SC actors on the supply and distribution side have to be included as well (multiple actors 45.6\%). Furthermore, from Table 8 we see that every second paper concentrates on the SC (chain 46.7\%). Hence, a network structure is considered implicitly rather than explicating it in the conceptual framework. 
Regarding the time horizon, risks lead to disturbances in the short term or disruptions in the long term, whereas security and resilience prevent their impact in these time horizons (Pfohl et al. 2010). Considering the risk origin, endogenous risks that are caused within the $\mathrm{SC}$ can be distinguished from exogenous risks that arise from the economic, ecological, and social environment (Heckmann et al. 2015; Giannakis and Papadopoulos 2016). Based on the TBL of sustainability, economic, environmental and social aspects can be either the cause for SC risks, while these TBL dimensions can be affected by SC risks (Heckmann et al. 2015). Conventional SC risks include supply, demand, product, and information risks (Tang 2006) that are determined by infrastructural, technological, and operational factors and external stakeholders. Industry specificities account for environmental and problemspecific factors, while organizational and decision-maker factors (Rao and Goldsby 2009) are related to the SC levels and actors.

The scope of the framework reflects a comprehensive view on stakeholder influences and sustainability-related SC risks. Stakeholder influences can cause and can also be affected by sustainability-related risks. Thus, the coherence of stakeholder triggers and SSCM risks needs to be conceptualized. The influence of financial markets on management decisions to mitigate environmental risks plays a central role in SSCM (see, e.g., Dam and Petkova 2014). Dobler et al. (2014) distinguish between regulatory, operational, and natural risks and find that environmental risk management positively affects the controlling of risks in operations, while natural risks appear to be decoupled from related measures. The authors emphasize that "remedial types of risk management", e.g., by addressing stakeholder pressure related to an acute incident, contribute to risk management, although neither the prevention nor the impact reduction of negative incidents is addressed (Dobler et al. 2014: 13).

From the coding, we observe that economic risks are mostly attributed to the focal company as a result of stakeholder influences leading to supply and demand risks. Company-internal stakeholders, shareholders, and investors are affected by economic risks, while from a macroscopic view, governmental authorities and the wider public are also interested in the economic performance, growth, and employment. Governmental policy incentives are particularly decisive for the promotion of sustainable SCs (Ding et al. 2016).

These observations illustrate that the coherence of stakeholder influences and SSCM risks needs to be reflected in scientific research. For instance, formal models may take into account demand risks while considering governmental pressures, e.g., in the form of carbon emission taxes for on- or offshore sourcing decisions (e.g., Choi 2013; Rosic and Jammernegg 2013).

\section{Discussion}

In this section, we justify our contributions in comparison to earlier studies. Finally, we give guidelines for future research directions. 


\subsection{Contribution in comparison to earlier studies}

Our results largely confirm the findings by Meixell and Luoma (2015), who find that customer, governmental, and a wide range of other stakeholder pressures are addressed by empirical studies. Furthermore, a similar share of holistic TBL orientation and economic-environmental studies is detected. Based on a bibliometric cluster analysis, Fahimnia et al. (2015) reveal sustainability risk management as an important, however underrepresented field of risk management research that is rapidly growing. The results of the study at hand confirm this observation and, in addition, exemplify the importance of linking conceptual and empirical studies to model-based research.

The additional coding categories selected for this paper lead to novel insights with regard to the actor and level of analysis and the industry foci. However, our study is limited by the paper sample, which only comprises articles that are listed in Web of Science and that cover the early years of a dynamic and evolving research area. As the field of research is quickly expanding, the study may need to be updated after some years.

We propose a conceptual framework that comprises different stakeholder categories, as suggested by Seuring and Müller (2008b). However, in contrast to frameworks designed by Seuring and Müller (2008b) or Brandenburg and Rebs (2015), the presented conceptual framework takes a broader SC perspective and covers not only different categories of SC actors, but also distinguishes between an internal and an external SC level. Moreover, the conceptual framework presented in the paper at hand incorporates constructs of widely accepted concepts of traditional SC risk management developed by Tang (2006), Rao and Goldsby (2009), Pfohl et al. (2010), and Heckmann et al. (2015). Thus, it offers a more comprehensive risk conceptualization than general SSCM frameworks presented earlier.

Regarding models and metrics, we observe that social criteria are still underrepresented, thus confirming findings from earlier studies (Miemczyk et al. 2012; Brandenburg and Rebs 2015). Moreover, the study at hand encourages the application of stochastic models. Such stochastic approaches can take into account different scenarios that address stakeholder triggers or the probability of events that disturb or disrupt the SC. In addition, the estimated impacts and consequences of such influences can be quantified. Stochastic models are appropriate to reflect vagueness and uncertainty, which is a major cause for SC risks, and, hence, could be considered instead of deterministic ones to numerically assess SC risks. These findings are in line with recommendations given by Fahimnia et al. (2015) and Brandenburg and Rebs (2015). In addition to earlier works, the presented work emphasizes the need to bridge the observed gap between conceptual, empirical, and model-based research and to consider mutual stimuli between these interlinked but currently fairly separated and independent research fields. 


\subsection{Guidelines for future qualitative and quantitative studies with a focus on stakeholder triggers and risks for SSCM}

In view of the major findings obtained on SSCM triggers and risks from this study, mutual stimuli between the different research designs are outlined, and guidelines for future research are proposed. In total, five recommendations are given.

(1) Link conceptual, empirical, and formal modeling research methods:

Our observations based on citation analysis suggest that stimuli between different research methods need to be strengthened in future research. Formal models help to validate conceptual frameworks and quantify the links between constructs that are often substantiated only by qualitative arguments or empirical observations. Correspondingly, empirical studies can help to test formal models, and quantitative analyses that are based on empirical data can lead to stronger findings than models simply illustrated at generic numerical examples. In short, we recommend strengthening the relationship between deductive and inductive research (Golicic et al. 2005) based on axiomatic and empirical models (Bertrand and Fransoo 2002). Required models and frameworks can be developed in the normal research cycle by iterating the steps of description, explanation, and testing (Meredith et al. 1989; Meredith 1993). The sequence and iteration of methodological steps, i.e., conceptualization, modeling, model solving, and implementation, may differ depending on individual research objectives (Mitroff et al. 1974). In this way, a better balance between inductive qualitative and deductive quantitative approaches in SCM research can be achieved (Golicic et al. 2005). Formal models and their solutions need to be fed back to and complemented by conceptual frameworks and empirical evidence. Moreover, the publication of real-world data sets together with the description of the analyzed problem (e.g., as a data in brief article) may stimulate further investigations.

(2) Operationalize the TBL dimensions of sustainability:

The operationalization of sustainability factors, e.g., by determining the financial impacts of sustainability practices, is a key complication when conceptualized constructs are translated into formal models for SSCM (Müller and Pfleger 2014). Different corporate functions are involved in SSCM, and reputation is a central lever when it comes to sustainability-related issues. Thus, cross-functional approaches, e.g., linking marketing and SC alignment (Leppelt et al. 2013b), should involve different forms of operationalization and scales of measurement. However, when conceptual or empirical results are transferred to formal models, the social aspects often get lost during this transition. Overall, approaches and frameworks for both environmental management and CSR could be formalized by model-based studies.

(3) Operationalize stakeholder influences for SSCM:

The operationalization of stakeholder influences on SSCM needs to be strengthened. Formal models support the evaluation of the effectiveness of regulatory pressures and incentives both for SSCM performance measurement 
and public policy-making. Stakeholder influences, in particular NGO pressure or consumer boycotts, are conceptually and empirically assessed and should now be transferred to formal models, e.g., with regard to reputational risk as a central lever for economic performance. It is striking that reputational risk and the resulting customer reaction, thus being an economic risk with regard to the sales figures, are emphasized by a remarkable share of conceptual and empirical studies. In contrast, the relevance and dominance of reputational risk are not observed for formal models. Hence, this gap in formal modeling research should be considered by future research. Finally, empirical analyses and conceptual studies reveal the importance of other stakeholder groups, in particular employees and shareholders as well as trade unions and the media. Incorporating the influences of these stakeholder groups may be one future direction for model-based SSCM research.

\section{(4) Operationalize risks in SSCM:}

The operationalization of SSCM risks leaves room for additional research. The conceptualization of environmental and social risks in the context of SCM is still fragmentary and systematizes specific risk factors using heterogeneous typologies, while the consideration of risks appears to become more relevant for scientific research and managerial practice (Reefke and Sundaram 2017). A comprehensive framework should be developed and linked with stakeholder triggers, which address economic, environmental, and social risk factors to take into account for SSCM. The definition and operationalization of environmental and social risks and their impact on economic SC performance is a crucial challenge for formal modeling in concert with case-based research. Empirical studies could validate the formal approaches to quantify and measure SSCM risks. Against this background, the practical applicability of complex models, which might be challenging to handle in real-life contexts, should be considered.

(5) Examine industry specifics and managerial implications:

Different application contexts offer new perspectives to assess stakeholder triggers and SSCM risks. Sustainability risks in the food and beverage SC, identified as a prominent industry focus in conceptual and empirical SSCM research, could be assessed by formal models. Agricultural production as well as food processing industries are central to sustain human life and exposed to a variety of environmental and social risks in an extremely dynamic SC environment of perishable goods. In addition to formal models, sustainability risks and stakeholder influences in the transportation sector could empirically be assessed. In general, the automotive industry, the retail sector, and the chemical and pharmaceutical industry are underrepresented research contexts in which economic, environmental, and social impacts need to be studied more thoroughly.

Recommendation (1) stresses the necessity to rethink the interplay between qualitative and quantitative approaches to research on stakeholder influences and risks in SSCM. In this way, the existing shortcomings of formal models to reflect sustainability-related stakeholder influences and risks in SCs could be overcome. From the results of content analysis, some examples become evident. Regarding the SC level of analysis, empirical studies that elaborate on more complex network 
structures and that validate respective formal models are needed. In particular, empirical research could shed further light on sustainable network design. Formal models should be stringently linked and tested with empirical data to ensure congruency of metrics and to support the validation of the model. Furthermore, the applicability and outcome (i.e., success and failure as well as advantages or disadvantages) of stakeholder and risk management concepts, strategies, and models should be investigated. This would also be subject to a discussion of underlying theories (e.g., stakeholder and agency theory) in the SSCM context.

Methodologically, recommendations (2), (3), and (4) point to the need to develop formal SSCM models that take into account all three dimensions of the TBL of sustainability as well as stakeholder influences and risks in SSCM. Related SSCM model types comprise optimization and simulation methods as well as hybrid models and analytical ones (Brandenburg et al. 2014). Optimization models and related solution methods may be limited by the problem or computational complexity that may arise from numerous stakeholder influences and complicate risk constructs. In such cases, heuristic approaches may be helpful to overcome such limitations. Furthermore, systems thinking and simulation approaches help in understanding the structure and behavior of complex supply networks in the presence of sustainability requirements. Thus, related modeling approaches should be considered to avoid a focused optimization of narrow scopes of analysis or partial systems. For instance, system dynamics modeling is deemed a useful research approach to investigate into long-term effects and time delays (Reefke and Sundaram 2017).

Hybrid modeling approaches that link different model types may reveal great potential to model the complexity of sustainable SCs, the influence of stakeholders, and involved risks to sustainable SC performance. However, hybrid modeling approaches necessitate thorough knowledge of researchers and research groups, which highlights the need to involve experts for conceptual and empirical research. In addition, inter-disciplinary backgrounds to contribute expert knowledge from economic, environmental, and social disciplines are crucial to tackle the challenges of managing SCs sustainably.

To further develop qualitative research approaches, i.e., conceptual and empirical studies that lay the foundation for the operationalization in formal models as well as for the validation of developed formal models, recommendation (5) addresses the need to broaden research foci to a wider variety of industries. Sustainability management research efforts initially concentrated on industries that are typically exposed to high sustainability-related risks, considerable stakeholder influences, and a significant impact on environmental and social systems, e.g., the food and beverage industries. However, as SSCM concepts and models are becoming increasingly mature, research foci should be broadened to a wider variety of industry sectors and SCs that involve different types of industries (see, e.g., Sauer and Seuring 2017), e.g., chemical SCs starting with metal and mining activities before refinement and subsequent processing to final chemical products take place. In this way, an overarching systems perspective of sustainable SCs can be approached and thus reflects the reality of interlinked economic, ecological, and social systems. 
Finally, the goal relationships between economic, environmental, and social objectives of operations and SC management create tensions that more often result in tradeoffs rather than in win-win (-win) situations. While operations and SCs in developed countries might bear the additional cost of environmental and social improvements, these tradeoffs should be minimized in emerging economics by a stronger focus on the financial bottom line (Esfahbodi et al. 2016). The recognition of the overall complexity of goal relationships between the TBL dimensions may be supported by a systems thinking perspective. In the end, methodological as well as technological advances will enhance the investigation into sustainable SCs and related decision-making.

\section{Conclusion}

The developments of SSCM research considering the stakeholder triggers and risk for SSCM performance are compared to point out commonalities and differences between conceptual, empirical, and formal modeling research. The systematic search for sample papers in Web of Science involves journal-specific searches in key journals in the field of logistics and SCM. The results of the analysis suggest that research considering stakeholder influences and risks in SSCM has just begun and that its future relevance will accelerate. Thus, considerable efforts are necessary to conceptualize and measure the interrelationships between stakeholder triggers for SSCM and sustainability-related SC risks. While governmental triggers are prevailing in related formal models, customer and other stakeholder triggers are dominating conceptual and empirical studies. Future research should take into account environmental and social risks in addition to the prevailing economic risk management. Moreover, formal models also need to integrate customer and other stakeholder groups. The operationalization of stakeholder influences and SSCM risks by formal models is highlighted as another future research area. Finally, an integrated view on stakeholder triggers and SSCM risks is advocated for SSCM research and practice to comprehensively control and sustain SC performance.

Open Access This article is distributed under the terms of the Creative Commons Attribution 4.0 International License (http://creativecommons.org/licenses/by/4.0/), which permits unrestricted use, distribution, and reproduction in any medium, provided you give appropriate credit to the original author(s) and the source, provide a link to the Creative Commons license, and indicate if changes were made.

\section{References}

Adams, M., and A. Ghaly. 2007. Maximizing sustainability of the costa rican coffee industry. Journal of Cleaner Production 15: 1716-1729.

Adriana, B. 2009. Environmental supply chain management in tourism: the case of large tour operators. Journal of Cleaner Production 17: 1385-1392.

Ahi, P., and C. Searcy. 2013. A comparative literature analysis of definitions for green and sustainable supply chain management. Journal of Cleaner Production 52: 329-341. 
Akkerman, R., P. Farahani, and M. Grunow. 2010. Quality, safety and sustainability in food distribution: a review of quantitative operations management approaches and challenges. OR Spectrum 32: 863-904.

Andersen, M., and T. Skjoett-Larsen. 2009. Corporate social responsibility in global supply chains. Supply Chain Management: An International Journal 14: 75-86.

Aneja, Y.P., and K.P.K. Nair. 1979. Bicriteria transportation problem. Management Science 25: 73-78.

Bai, C., and J. Sarkis. 2010. Integrating sustainability into supplier selection with grey system and rough set methodologies. International Journal of Production Economics 124: 252-264.

Bektas, T., and G. Laporte. 2011. The Pollution-Routing Problem. Transportation Research Part B 45: $1232-1250$.

Bertrand, J.W.M., and J.C. Fransoo. 2002. Operations management research methodologies using quantitative modeling. International Journal of Operations and Production Management 22: 241-264.

Beske, P., and S. Seuring. 2014. Putting Sustainability into Supply Chain Management. Supply Chain Management: An International Journal 19: 322-333.

Bourlakis, M., G. Maglaras, E. Aktas, D. Galleear, and C. Fotopoulos. 2014. Firm size and sustainable performance in food supply chains: insights from Greek SMEs. International Journal of Production Economics 152: 112-130.

Brandenburg, M., K. Govindan, J. Sarkis, and S. Seuring. 2014. Quantitative models for sustainable supply chain management: developments and directions. European Journal of Operational Research 233: 299-312.

Brandenburg, M., and T. Rebs. 2015. Sustainable supply chain management: a modeling perspective. Annals of Operations Research 229: 213-252.

Carter, C.R., and P.L. Easton. 2011. Sustainable supply chain management: evolution and future directions. International Journal of Physical Distribution and Logistics Management 41: 46-62.

Carter, C.R., and D.S. Rogers. 2008. A framework of sustainable supply chain management: moving toward new theory. International Journal of Physical Distribution and Logistics Management 38: 360-387.

Chen, J., and S. Slotnick. 2014. Supply chain disclosure and ethical sourcing. International Journal of Production Economics 161: 17-30.

Chkanikova, O., and M. Lehner. 2014. Private eco-brands and green market development: towards new forms of sustainability governance in the food retailing. Journal of Cleaner Production 107: 74-84.

Choi, T.M. 2013. Local sourcing and fashion quick response system: the impacts of carbon footprint tax. Transportation Research Part E 55: 43-54.

Choi, T.-S., X. Ye, L. Zhao, and A.C. Luo. 2016. Optimizing enterprise risk management: a literature review and critical analysis of the work of Wu and Olson. Annals of Operations Research 237: 291-300.

Christopher, M., C. Mena, O. Khan, and O. Yurt. 2011. Approaches to managing global sourcing risk. Supply Chain Management: An International Journal 16: 67-81.

Clarkson, M.B.E. 1995. A stakeholder framework for analyzing and evaluating corporate social performance. Academy of Management Review 20: 92-117.

Colicchia, C., and F. Strozzi. 2012. Supply chain risk management: a new methodology for a systematic literature review. Supply Chain Management: An International Journal 17: 403-418.

Corbett, J.J., and G.A. DeCroix. 2001. Shared-savings contracts for indirect materials in supply chains: channel profits and environmental impacts. Management Science 47: 881-893.

Corbett, J.J., H. Wang, and J.J. Winebrake. 2009. The effectiveness and costs of speed reductions on emissions from international shipping. Transportation Research Part D 14: 593-598.

Cousins, P., R. Lamming, and F. Bowen. 2004. The role of risk in environment-related supplier initiatives. International Journal of Operations and Production Management 24: 554-565.

Cruz, J.M. 2008. Dynamics of supply chain networks with corporate social responsibility through integrated environmental decision-making. European Journal of Operational Research 184: 1005-1031.

Cruz, J.M. 2009. The impact of corporate social responsibility in supply chain management: multicriteria decision-making approach. Decision Support Systems 48: 224-236.

Cruz, J.M. 2013a. Mitigating global supply chain risks through corporate social responsibility. International Journal of Production Research 51: 3995-4010.

Cruz, J.M. 2013b. Modeling the relationship of globalized supply chains and corporate social responsibility. Journal of Cleaner Production 56: 73-85. 
Cruz, J.M., and D. Matsypura. 2009. Supply chain networks with corporate social responsibility through integrated environmental decision-making. International Journal of Production Research 47: 621-648.

Diabat, A., D. Kannan, and K. Mathiyazhagan. 2014. Analysis of enablers for implementation of sustainable supply chain management: a textile case. Journal of Cleaner Production 83: 391-403.

Dam, L., and B. Petkova. 2014. The impact of environmental supply chain sustainability programs on shareholder wealth. International Journal of Operations and Production Management 34: 586-609.

Ding, H., Q. Liu, and L. Zheng. 2016. Assessing the economic performance of an environmental sustainable supply chain in reducing environmental externalities. European Journal of Operational Research 255: 463-480.

Dobler, M., K. Lajili, and D. Zéghal. 2014. Environmental Performance, Environmental Risk and Risk Management. Business Strategy and the Environment 23: 1-17.

Dou, Y., and J. Sarkis. 2010. A joint location and outsourcing sustainability analysis for a strategic offshoring decision. International Journal of Production Research 48: 567-592.

Dyllick, T., and K. Hockerts. 2002. Beyond the business case for corporate sustainability. Business Strategy and the Environment 11: 130-141.

Eisenhardt, K.M. 1989. Agency theory: an assessment and review. Academy of Management Review 14: 57-74.

Elkington, J. 1998. Cannibals with Forks: The Triple Bottom Line of the 21st Century. Stoney Creek/CT: New Society.

Eng-Larsson, F., and A. Norrman. 2014. Modal shift for greener logistics-exploring the role of the contract. International Journal of Physical Distribution \& Logistics Management 44: 721-743.

Esfahbodi, A., Y. Zhang, and G. Watson. 2016. Sustainable supply chain management in emerging economies: trade-offs between environmental and cost performance. International Journal of Production Economics 181: 350-366.

Fagerholt, K., G. Laporte, and I. Norstad. 2010. Reducing fuel emissions by optimizing speed on shipping routes. Journal of the Operational Research Society 61: 523-529.

Fahimnia, B., C.S. Tang, H. Darzani, and J. Sarkis. 2015. Quantitative models for managing supply chain risks: a review. European Journal of Operational Research 247: 1-15.

Fayezi, S., A. O'Loughlin, and A. Zutshi. 2012. Agency theory and supply chain management: a structured literature review. Supply Chain Management: An International Journal 17: 556-570.

Ferretti, I., S. Zanoni, L. Zavanella, and A. Diana. 2007. Greening the aluminium supply chain. International Journal of Production Economics 108: 236-245.

Fink, A. 2009. Conducting research literature reviews. Sage Publications.

Foerstl, K., A. Azadegan, T. Leppelt, and E. Hartmann. 2014. Drivers of supplier sustainability: moving beyond compliance to commitment. Journal of Supply Chain Management 51: 67-92.

Freeman, R.E. 1984. Strategic Management: A Stakeholder Approach. Financial Times Prentice Hall.

Freeman, R.E. 2010. Strategic management: a stakeholder approach. Cambridge: Cambridge University Press.

von Geibler, J. 2013. Market-based governance for sustainability in value chains: conditions for successful standard setting in the palm oil sector. Journal of Cleaner Production 56: 39-53.

Georgopoulou, E., Y. Sarafidis, and D. Diakoulaki. 1998. Design and implementation of a group DSS for sustaining renewable energies exploitation. European Journal of Operational Research 109: $483-500$.

Ghadge, A., S. Dani, and R. Kalawsky. 2012. Supply chain risk management: present and future scope. The International Journal of Logistics Management 23: 313-339.

Giannakis, M., and T. Papadopoulos. 2016. Supply chain sustainability: a risk management approach. International Journal of Production Economics 171: 455-470.

Golicic, S.L., D.F. Davis, and T.M. McCarthy. 2005. A balanced approach to research in supply chain management. In Research methodologies in supply chain management, ed. H. Kotzab, S. Seuring, M. Müller, and G. Reiner, 15-30. Heidelberg: Physica.

Govindan, K., S. Azevedo, H. Carvalho, and V. Cruz-Machado. 2014a. Impact of supply chain management practices on sustainability. Journal of Cleaner Production 85: 212-225.

Govindan, K., M. Kaliyan, D. Kannan, and A. Haq. 2014b. Barriers analysis for green supply chain management implementation in Indian industries using analytic hierarchy process. International Journal of Production Economics 147: 555-568. 
Govindan, K., H. Soleimani, and D. Kannan. 2015. Reverse logistics and closed-loop supply chain: a comprehensive review to explore the future. European Journal of Operational Research 240: 603-626.

Govindan, K., and H. Soleimani. 2017. A review of reverse logistics and closed-loop supply chains: a journal of cleaner production focus. Journal of Cleaner Production 142: 371-384.

Grekova, K., H. Bremmers, J. Trienekens, R. Kemp, and S. Omta. 2014. Extending environmental management beyond the firm boundaries: an empirical study of Dutch food and beverage firms. International Journal of Production Economics 152: 174-187.

Grimm, J., J. Hofstetter, and J. Sarkis. 2014. Critical factors for sub-supplier management: a sustainable food supply chains perspective. International Journal of Production Economics 152: 159-173.

Halldórsson, Á., and J.S. Arlbjørn. 2005. Research Methodologies in Supply Chain Management - What Do We Know? In Research methodologies in supply chain management, ed. H. Kotzab, S. Seuring, M. Müller, and G. Reiner, 107-122. Heidelberg: Physica.

Handfield, R., S.V. Walton, R. Sroufe, and S.A. Melnyk. 2002. Applying environmental criteria to supplier assessment: a study in the application of the analytical hierarchy process. European Journal of Operational Research 141: 70-87.

Hartmann, J., and S. Moeller. 2014. Chain liability in multitier supply chains? Responsibility attributions for unsustainable supplier behavior. Journal of Operations Management 32: 281-294.

Heckmann, I., T. Comes, and S. Nickel. 2015. A critical review on supply chain risk-definition, measure and modeling. Omega 52: 119-132.

Ho, W., T. Zheng, H. Yildiz, and S. Talluri. 2015. Supply chain risk management: a literature review. International Journal of Production Research 53: 5031-5069.

Hofmann, H., C. Busse, C. Bode, and M. Henke. 2014. Sustainability-related supply chain risks: conceptualization and management. Business Strategy and the Environment 23: 160-172.

Holweg, M., and D.P. van Donk. 2009. When is a conceptual framework also a theoretical contribution? In Operations and Supply Management (OMS) Forum. 1-3.

Iles, A. 2007. Making the seafood industry more sustainable: creating production chain transparency and accountability. Journal of Cleaner Production 15: 577-589.

Jaehn, F. 2016. Sustainable operations. European Journal of Operations Research 253: 243-264.

Janic, M. 2011. Assessing some social and environmental effects of transforming an airport into a real multimodal transport node. Transportation Research Part D 16: 137-149.

Kainuma, Y., and N. Tawara. 2006. A multiple attribute utility theory approach to lean and green supply chain management. International Journal of Production Economics 101: 99-108.

Khan, O., and B. Burnes. 2007. Risk and supply chain management: creating a research agenda. The International Journal of Logistics Management 18: 197-216.

Koplin, J., S. Seuring, and M. Mesterharm. 2007. Incorporating sustainability into supply management in the automotive industry-the case of the Volkswagen AG. Journal of Cleaner Production 15: 1053-1062.

Krippendorff, K. 1980. Content analysis. Beverly Hills/CA: Sage.

Leppelt, T., K. Foerstl, C. Reuter, and E. Hartmann. 2013a. Sustainability management beyond organizational boundaries - sustainable supplier relationship management in the chemical industry. Journal of Cleaner Production 56: 94-102.

Leppelt, T., K. Foerstl, and E. Hartmann. 2013b. Corporate social responsibility in buyer-supplier relationships: is it beneficial for top-tier suppliers to market their capability to ensure a responsible supply chain? Business Research 6: 126-152.

Lindahl, P., K. Robert, H. Ny, and G. Broman. 2014. Strategic sustainability considerations in materials management. Journal of Cleaner Production 64: 98-103.

Lorek, S., and J.H. Spangenberg. 2014. Sustainable consumption within a sustainable economy beyond green growth and green economies. Journal of Cleaner Production 63: 33-44.

Lu, L.Y.Y., C.H. Wu, and T.C. Kuo. 2007. Environmental principles applicable to green supplier evaluation by using multi-objective decision analysis. International Journal of Production Research 45: 4317-4331.

Massoud, M., R. Fayad, M. El-Fadel, and R. Kamleh. 2010. Drivers, barriers and incentives to implementing environmental management systems in the food industry: a case of Lebanon. Journal of Cleaner Production 18: 200-209.

Matos, S., and J. Hall. 2007. Integrating sustainable development in the supply chain: the case of life cycle assessment in oil and gas and agricultural biotechnology. Journal of Operations Management 25: 1083-1102. 
Mayring, P. 2010. Qualitative Inhaltsanalyse: Grundlagen und Techniken [Qualitative Content Analysis: Basics and Techniques]. Weinheim: Beltz.

McDonald, S., and S. Young. 2012. Cross-sector collaboration shaping corporate social responsibility best practice within the mining industry. Journal of Cleaner Production 37: 54-67.

McLellan, B., and G. Corder. 2013. Risk reduction through early assessment and integration of sustainability in design in the minerals industry. Journal of Cleaner Production 53: 37-46.

Meixell, M.J., and P. Luoma. 2015. Stakeholder pressure in sustainable supply chain management. International Journal of Physical Distribution and Logistics Management 45: 69-89.

Meredith, J., A. Raturi, K. Amoako-Gyampah, and B. Kaplan. 1989. Alternative research paradigms in operations. Journal of Operations Management 8: 297-326.

Meredith, J. 1993. Theory building through conceptual methods. International Journal of Operations and Production Management 13: 3-11.

Michaelis, L. 2003. The role of business in sustainable consumption. Journal of Cleaner Production 11: 915-921.

Miemczyk, J., T. Johnsen, and M. Macquet. 2012. Sustainable purchasing and supply management: a structured literature review of definitions and measures at the dyad, chain and network levels. Supply Chain Management: An International Journal 17: 478-496.

Mitroff, I.I., F. Betz, L.R. Pondy, and F. Sagasti. 1974. On managing science in the systems age: two schemas for the study of science as a whole systems phenomenon. Interfaces 4: 46-58.

Moore, S., and L. Ausley. 2004. Systems thinking and green chemistry in the textile industry: concepts, technologies and benefits. Journal of Cleaner Production 12: 585-601.

Moore, S., and S. Manring. 2009. Strategy development in small and medium sized enterprises for sustainability and increased value creation. Journal of Cleaner Production 17: 276-282.

Müller, A.-L., and R. Pfleger. 2014. Business transformation towards sustainability. Business Research 7: 313-350.

Nagurney, A., and F. Toyasaki. 2003. Supply chain supernetworks and environmental criteria. Transportation Research Part E 8: 185-213.

Ni, D., and K.W. Li. 2012. A game-theoretic analysis of social responsibility conduct in two-echelon supply chains. International Journal of Production Economics 138: 303-313.

Noci, G. 1997. Designing 'green' vendor rating systems for the assessment of a supplier's environmental performance. European Journal of Purchasing and Supply Management 3: 103-114.

Oliveira, C., and C. Henggeler Antunes. 2004. A multiple objective model to deal with economy-energyenvironment interactions. European Journal of Operational Research 153: 370-385.

Pagell, M., Z. Wu, and M. Wassermann. 2010. Thinking differently about purchasing Portfolios: an assessment of sustainable sourcing. Journal of Supply Chain Management 46: 57-73.

Pagell, M., and A. Shevchenko. 2014. Why research in sustainable supply chain management should have no future. Journal of Supply Chain Management 50: 44-55.

Pfohl, H.C., H. Köhler, and D. Thomas. 2010. State of the art in supply chain risk management research: empirical and conceptual findings and a roadmap for the implementation in practice. Logistics Research 2: 33-44.

Quak, H., and M. De Koster. 2007. Exploring retailers' sensitivity to local sustainability policies. Journal of Operations Management 25: 1103-1122.

Quak, H., and M. De Koster. 2009. Delivering goods in urban areas: how to deal with urban policy restrictions and the environment. Transportation Science 43: 211-227.

Ramudhin, A., A. Chaabane, and M. Paquet. 2010. Carbon market sensitive sustainable supply chain network design. International Journal of Management Science and Engineering Management 5: 30-38.

Rangel, D.A., T.K. de Oliveira, and M.S.A. Leite. 2015. Supply chain risk classification: discussion and proposal. International Journal of Production Research 53: 6868-6887.

Rao, S., and T.J. Goldsby. 2009. Supply chain risks: a review and typology. The International Journal of Logistics Management 20: 97-123.

Reefke, H., and D. Sundaram. 2017. Key themes and research opportunities in sustainable supply chain management-identification and evaluation. Omega 66: 195-211.

Reuter, C., K. Foerstl, E. Hartmann, and C. Blome. 2010. Sustainable global supplier management: the role of dynamic capabilities in achieving competitive advantage. Journal of Supply Chain Management 46: 45-65.

Rizzi, F., M. Frey, F. Testa, and A. Appolloni. 2014. Environmental value chain in green SME networks: the threat of the Abilene paradox. Journal of Cleaner Production 85: 1-11. 
Roehrich, J., J. Grosvold, and S. Hoejmose. 2014. Reputational risks and sustainable supply chain management: decision making under bounded rationality. International Journal of Operations and Production Management 34: 695-719.

Rosic, H., and W. Jammernegg. 2013. The economic and environmental performance of dual sourcing: a newsvendor approach. International Journal of Production Economics 143: 109-119.

Sauer, P.C., and S. Seuring. 2017. Sustainable supply chain management for minerals. Journal of Cleaner Production 151: 235-249.

Severo, E., J. Ferro de Guimaraes, E. Henri Dorion, and C. Hermann Nodari. 2014. Cleaner production, environmental sustainability and organizational performance: an empirical study in the Brazilian Metal-Mechanic industry. Journal of Cleaner Production 96: 118-125.

Seuring, S. 2013. A review of modeling approaches for sustainable supply chain management. Decision Support Systems 54: 1513-1520.

Seuring, S., and M. Müller. 2008a. Core issues in sustainable supply chain management—a Delphi Study. Business Strategy and the Environment 17: 455-466.

Seuring, S., and M. Müller. 2008b. From a literature review to a conceptual framework for sustainable supply chain management. Journal of Cleaner Production 16: 1699-1710.

Seuring, S., and S. Gold. 2012. Conducting content-analysis based literature reviews in supply chain management. Supply Chain Management: An International Journal 17: 544-555.

Shapiro, J. 2007. Modeling the supply chain. Duxbury: Brooks/Cole, Thompson.

Spens, K.M., and G. Kovács. 2006. A content analysis of research approaches in logistics research. International Journal of Physical Distribution and Logistics Management 36: 374-390.

Tang, C.S. 2006. Perspectives in supply chain risk management. International Journal of Production Economics 103: 451-488.

Ting, S., Y. Tse, G. Ho, S. Chung, and G. Pang. 2014. Mining logistics data to assure the quality in a sustainable food supply chain: a case in the red wine industry. International Journal of Production Economics 152: 200-209.

Tranfield, D., D. Denyer, and P. Smart. 2003. Towards a methodology for developing evidence-informed management knowledge by means of systematic review. British Journal of Management 14: 207-222.

Tukamuhabwa, B.R., M. Stevenson, J. Busby, and M. Zorzini. 2015. Supply chain resilience: definition, review and theoretical foundations for further study. International Journal of Production Research 53: 5592-5623.

Walther, G., A. Schatka, and T.S. Spengler. 2012. Design of regional production networks for second generation synthetic bio-fuel-a case study in Northern Germany. European Journal of Operational Research 218: 280-292.

Whetten, D.A. 1989. What constitutes a theoretical contribution? The Academy of Management Review 14: 490-495.

Wu, Z., and M. Pagell. 2011. Balancing priorities: decision-making in sustainable supply chain management. Journal of Operations Management 29: 577-590.

Yawar, S.A., and S. Seuring. 2017. Management of social issues in supply chains: a literature review exploring social issues, actions and performance outcomes. Journal of Business Ethics 141: 621-643.

Zhu, Q., J. Sarkis, and Y. Geng. 2005. Green supply chain management in China: pressures, practices and performance. International Journal of Operations \& Production Management 25: 4333-4355.

\section{Publisher's Note}

Springer Nature remains neutral with regard to jurisdictional claims in published maps and institutionalaffiliations. 